\title{
Synthesis and Characterization of Antibacterial Carbopol/ZnO Hybrid Nanoparticles Gel
}

\author{
Sameh H. Ismail ${ }^{1}\left(\mathbb{D}\right.$, Ahmed Hamdy ${ }^{1,2} \mathbb{D}$, Tamer Ahmed Ismail ${ }^{3} \mathbb{D}$, Heba H. Mahboub ${ }^{4}$, Walaa H. Mahmoud ${ }^{5}$ \\ and Walid M. Daoush $6,7, * \mathbb{D}$
}

1 Faculty of Nanotechnology for Postgraduate Studies, Sheikh Zayed Campus, Cairo University, 6th October City, Giza 12588, Egypt; drsameheltayer@yahoo.com (S.H.I.); ahsadek@zewailcity.edu.eg (A.H.)

2 Environmental Engineering Program, Zewail City of Science, Technology and Innovation, 6th October City, Giza 12578, Egypt

3 Department of Clinical Laboratory Sciences, Turabah University College, Taif University, P.O. Box 11099, Taif 21944, Saudi Arabia; t.ismail@tu.edu.sa

4 Department of Fish Diseases and Management, Faculty of Veterinary Medicine, Zagazig University, P.O. Box 44511, Sharkia 44519, Egypt; Hebamahboub@zu.eg

5 Faculty of Science, Cairo University, Giza 12613, Egypt; wmahmoud@sci.cu.edu.eg

6 Department of Chemistry, College of Science, Imam Mohammad ibn Saud Islamic University (IMSIU), Othman ibn Affan St., P.O. Box 5701, Riyadh 11432, Saudi Arabia

7 Department of Production Technology, Faculty of Technology and Education, Helwan University, Saray-El Qoupa, El Sawah Street, Cairo 11281, Egypt

* Correspondence: wmdaoush@imamu.edu.sa

Citation: Ismail, S.H.; Hamdy, A.; Ismail, T.A.; Mahboub, H.H.;

Mahmoud, W.H.; Daoush, W.M. Synthesis and Characterization of Antibacterial Carbopol/ZnO Hybrid Nanoparticles Gel. Crystals 2021, 11, 1092. https://doi.org/10.3390/ cryst11091092

Academic Editor: Leonid Kustov

Received: 1 August 2021

Accepted: 2 September 2021

Published: 7 September 2021

Publisher's Note: MDPI stays neutral with regard to jurisdictional claims in published maps and institutional affiliations.

Copyright: (C) 2021 by the authors. Licensee MDPI, Basel, Switzerland. This article is an open access article distributed under the terms and conditions of the Creative Commons Attribution (CC BY) license (https:/ / creativecommons.org/licenses/by/ $4.0 /)$.

\begin{abstract}
This study recommends Carbopol/zinc oxide $(\mathrm{ZnO})$ hybrid nanoparticles gel as an efficient antibacterial agent against different bacterial species. To this end, $\mathrm{ZnO}$ nanoparticles were synthesized using chemical precipitation derived from a zinc acetate solution with ammonium hydroxide as its precipitating agent under the effect of ultrasonic radiation. The synthesized $\mathrm{ZnO}$ nanoparticles were stabilized simultaneously in a freshly prepared Carbopol gel at a $\mathrm{pH}$ of 7 . The chemical composition, phase identification, particle size and shape, surface charge, pore size distribution, and the BET surface area of the $\mathrm{ZnO}$ nanoparticles, as well as the Carbopol/ZnO hybrid Nanoparticles gel, were by XRD, SEM, TEM, AFM, DLS, Zeta potential and BET instruments. The results revealed that the synthesized $\mathrm{ZnO}$ nanoparticles were well-dispersed in the Carbopol gel network, and have a wurtzite-crystalline phase of spherical shape. Moreover, the Carbopol/ZnO hybrid nanoparticles gel exhibited a particle size distribution between $\sim 9$ and $\sim 93 \mathrm{~nm}$, and a surface area of $54.26 \mathrm{~m}^{2} / \mathrm{g}$. The synthesized Carbopol/ZnO hybrid nanoparticles gel underwent an antibacterial sensitivity test against gram-negative K. pneumonia (ATCC 13883), Bacillus subtilis (ATCC 6633), and gram-positive Staphylococcus aureus (ATCC 6538) bacterial strains, and were compared with ampicillin as a reference antibiotic agent. The obtained results demonstrated that the synthesized Carbopol/ZnO hybrid nanoparticles gel exhibited a compatible bioactivity against the different strains of bacteria.
\end{abstract}

Keywords: ZnO nanoparticles; hybrid materials; chemical precipitation; Carbopol; BET surface area; zeta-potential; antibacterial activity

\section{Introduction}

In recent decades, discussions focused on the application of biomedical nanomaterials have increased in the medical field due to their eminent biological properties. With their broad applications in various fields, metal oxide nanoparticles have shown far-reaching and promising prospects in the field of biomedicine, especially for drug delivery/antibacterial genes, biosensing, cytometry, cancer, and others [1-3].

Many synthetic techniques are used for the synthesis of zinc oxide nanoparticles ( $\mathrm{ZnO}$ NPs). These methods could be classified into three main types: physical, chemical, and biological methods. Furthermore, chemical synthesis includes liquid-phase synthesis and 
gas-phase synthesis. Liquid phase synthesis involves some sub-methods, such as polyol [4], sonochemical [5], solvothermal [6], hydrothermal [7], water-oil microemulsions [8], sol-gel processing [9], co-precipitation [10], and precipitation methods [11], while methods such as inert gas condensation and pyrolysis fall within fabrication methods in the vapor phase [12] $\mathrm{ZnO}$ NPs are classified as II-VI semiconductors and are characterized by a high excitation energy of $60 \mathrm{eV}$ and wide band gap energy of $3.3 \mathrm{eV}$. Thus, they can tolerate large electric fields, high temperatures, and high power operations [13]. These properties make $\mathrm{ZnO}$ NPs highly applicable in chemical sensors, photocatalysis, and solar cells [14]. Additionally, the crystal structure of ZnO NPs significantly contributes to the emergence of their piezoelectric properties. Accordingly, this makes $\mathrm{ZnO}$ NPs suitable for acoustic wave resonators and acoustic-optic modulators. In addition, the Centro-symmetric structure of ZnO NPs made them the highest tensors among all semiconductors, providing a large electromechanical coupling [15]. Moreover, the GRAS substances (SCOGS) database allows access to opinions and conclusions from 115 SCOGS reports published between 1972-1980 on the safety of over 370 Generally Recognized as Safe (GRAS) food substances by the U.S. Food and Drug Administration (FDA). Accordingly, the Select Committee on GRAS Substances (SCOGS) opinion concluded that there is no evidence in the available information on zinc oxide that demonstrates, or suggests reasonable grounds to suspect, a hazard to the public [16].

Additionally, ZnO NPs are commonly used in various fields due to their distinct physical and chemical properties as one of the most important semiconductor metal oxide nanoparticles $[17,18]$. Because of the ability of $\mathrm{ZnO}$ to absorb $\mathrm{UV}$ radiation, it is increasingly used in personal care products, such as sunscreens and cosmetics [19]. ZnO NPs have also been applied in the rubber industry as they can provide the abrasion resistance for the rubber composite, as well as improve the high polymer performance in anti-aging, toughness and strength, and other functions [20]. In addition, ZnO NPs have excellent antibacterial and antimicrobial properties. Furthermore, when used in the textile industry, fabrics treated with the addition of ZnO NPs gain attractive properties, such as UV blocking, visible light resistance, deodorant, and antibacterial agents [21,22]. Zinc oxide can also be used in other branches of industry, including electronics, photocatalysis, concrete production, and other technologies $[23,24]$.

These hydrogels are three-dimensional systems of hydrophilic polymers, which can swell when absorbing water; however, they do not dissolve. Moreover, these hydrogels can interact with the surrounding environments and simultaneously exhibit changes in both their chemical and physical properties $[25,26]$. Great efforts have been exerted on hydrogels containing $\mathrm{pH}$ and / or temperature-sensitive properties due to their extraordinary potential in bioengineering and biomedical uses, especially in cell culture, molecular separation, and drug release $[27,28]$. The term "nanogel" was introduced to define the cross-linked dual-functional networks of a polyion and a nonionic polymer for polynucleotide delivery $[29,30]$. Nanogels are composed of nanoparticles that are formed by physically or chemically cross-linked polymer networks that stabilize and swell in a fine solvent [31,32]. Breakthroughs in nanotechnology have generated the need to develop nanogel systems which demonstrate the ability to deliver drugs in controlled, stable, and targetable settings. With the promising field of polymer science, it is now possible to develop smart nanoscale systems which could provide effective treatments and diagnoses, as well as advance clinical trials [33,34]. Carbopol 940, or Carbomer 940, is a synthetic high-molecular-weight polymer of the acrylic acid monomer. They may be homopolymers of acrylic acid or cross-linked with an allyl ether of propylene, allyl ether of sucrose, or an allyl ether of pentaerythritol. Carbopol 940 contains not less than $56 \%$ and not more than $68 \%$ of carboxylic $(-\mathrm{COOH})$ groups. The viscosity of a neutralized $0.5 \%$ aqueous dispersion of Carbopol 940 is between 40,000 and 60,000 centipoises [35]. In an aqueous solution of a neutral pH, Carbopol 940 is an anionic polymer, i.e., many of the side chains of Carbopol 940 will lose their protons and acquire a negative charge. This gives Carbopol 940 polyelectrolytes the ability to absorb and retain water and swell to many times their original volume [36]. Dry Carbopol 940 is produced as white, fluffy powders that are frequently used as gels in personal care and 
cosmetic products. Their role in cosmetics is to suspend solids in liquids, prevent emulsions from separating, and to control the consistency in the flow of cosmetics. Carbopol codes $(910,934,940,941$, and 934P) are an indication of molecular weight and the specific components of the polymer [37]. For many applications, Carbopol 940 is used in form of alkali metal or ammonium salts, e.g., sodium polyacrylate. In the dry powder form, the positively charged sodium ions are bonded to the polyacrylate; however, in aqueous solutions, the sodium ions can be dissociated. Instead of the formation of an organized polymer chain, this leads to a swollen gel that can absorb a high amount of water [38].

The targets of synthesis and fabrication of any antimicrobial compound are to inhibit the causal microbe without any side effects on the patients. Besides, it is worthy to stress here the basic idea of applying any chemotherapeutic agent, which depends essentially on the specific control of at least one biological function while avoiding multiple ones. $\mathrm{ZnO}$ nanogel exhibits good and effective antimicrobial and antibacterial activity. It is highly selective in bactericidal activity and reveals biocompatibility as well as low effects in human cells [39-41]. ZnO nanogel delays the microbial growth of foodborne pathogens, such as B. subtilis, E. coli, Pseudomonas fluorescent, etc. In vitro culture, media studies showed that $\mathrm{ZnO}$ nanogel is very effective at killing microbes such as $S$. enteritidis, E. coli, Listeria monocytogenes, and others [42,43]. ZnO nanoparticles of about 10-25 nm particle size can penetrate deeply into the ventral cell and enhance its membrane permeability. They disintegrate and produce complete sets of bacterial and microbial cell membranes [18]. There are several types of mechanisms that explain the antimicrobial and antibacterial activities of $\mathrm{ZnO}$ nanogel. Complete cell lysis and an elevation in membrane permeability due to the production of hydrogen peroxide $\left(\mathrm{H}_{2} \mathrm{O}_{2}\right)$ from the $\mathrm{ZnO}$ nanoscale surface, are some of the most recognized mechanisms within the scientific community [44,45]. The size of the $\mathrm{ZnO}$ nanogel is very important for its activity; it is shown that the smaller sizes of $\mathrm{ZnO}$ nanoparticles per unit volume in the aqueous medium increase the surface area and enhance the production of hydrogen particles [46,47]. Another study reported that the production of zinc particles causes severe damage to the bacterial cell membrane. This results in the formation of small pores on the cell surface and leads to leakage of cellular contents, causing bacterial cell death [48-50].

Furthermore, many researchers have used Carbopol-based inorganic metal/metal oxides nanoparticles and organic additive hybrid systems in different fields. For example, Jana et al. have used Carbopol gel containing chitosan-egg albumin nanoparticles for transdermal aceclofenac delivery [51], while Sareen et al. have formulated and evaluated the meloxicam Carbopol-based gels for drug release uses [52]. In addition, Bonacucina et al. have analyzed the thickening properties of Carbopol 974 and 971 in a 50:50 mixture of water/Silsense ${ }^{\mathrm{TM}} \mathrm{A}-21$ as a new cationic silicon miscible in any proportion with water. In addition, they have also evaluated the rheological properties of Silicon/Carbopol hydrophilic gel systems as a vehicle for the delivery of water-insoluble drugs [53].

In this study, $\mathrm{ZnO}$ nanoparticles were synthesized using chemical precipitation derived from a zinc acetate solution with ammonium hydroxide as its precipitating agent under the effect of ultrasonic radiation. The prepared $\mathrm{ZnO}$ NPs were stabilized using Carbopol gel to obtain a hybrid system of well-dispersed nanoparticles in the gel network. Similarly, the synthesized Carbopol/ZnO hybrid nanoparticles gel was also successfully prepared using a chemical precipitation reaction in a Carbopol stabilizing agent under the effect of ultrasonic irradiation. The chemical composition, phase identification, adsorption/desorption behavior, and pore size distribution properties of ZnO NPs and Carbopol/ZnO hybrid nanoparticles gel were evaluated by XRD and BET analyzers. In addition, topographical and morphological textures of the synthesized ZnO NPs, as well as the Carbopol/ZnO hybrid nanoparticles gel, have been investigated using AFM, SEM, and TEM microscopies. DLS and zeta-potential studies were also conducted to investigate the size distribution and charge measurements of the prepared $\mathrm{ZnO}$ NPs and Carbopol/ZnO hybrid nanoparticles gel, respectively. Finally, the synthesized Carbopol/ZnO hybrid nanoparticles gel was examined as antibacterial nanoparticles/gel hybrid system against 
gram-negative K. pneumonia (ATCC 13883) and gram-positive (Bacillus subtilis (ATCC 6633) and Staphylococcus aureus (ATCC 6538) bacterial strains.

\section{Experimental Section}

\subsection{Preparation of $\mathrm{ZnO}$ NPs and Carbopol/ZnO Hybrid Nanoparticles Gel}

$\mathrm{ZnO} N \mathrm{~N}$ s were synthesized using the chemical precipitation method under the effect of ultrasound irradiation. In a typical procedure, zinc acetate dihydrate $\left(\mathrm{Zn}\left(\mathrm{CH}_{3} \mathrm{COO}\right)_{2} \cdot 2 \mathrm{H}_{2} \mathrm{O}\right.$, Loba Chemie, Mumbai, India) as a precursor, and an ammonia solution of $30-33 \%\left(\mathrm{NH}_{3}\right)$ in an aqueous solution ( $\mathrm{NH}_{4} \mathrm{OH}$, Advent chembio, Mumbai, India) as a reducing agent, were used [54]. The $\mathrm{ZnO}$ nanoparticles were produced by dissolving the appropriate amount of zinc acetate in $100 \mathrm{~mL}$ of deionized water to produce $0.1 \mathrm{M}$ of a zinc ions solution. Subsequently, the zinc ions solution was subjected to ultrasonic wave irradiation using a Hielscher UP400S ( 400 W, $24 \mathrm{kHz}$, Berlin, Germany) at an amplitude of $79 \%$ and a cycle of 0.76 for $5 \mathrm{~min}$ at a temperature of $40^{\circ} \mathrm{C}$. Then, the ammonia solution was added dropwise to the zinc ions solution under the effect of the ultrasonic waves. After few moments, the ZnO NPs began to precipitate and grow, and the ammonia solution was continuously added until the complete precipitation of $\mathrm{ZnO}$ NPs occurred.

The obtained ZnO NPs were washed using deionized water several times and were left out to settle down. Posteriorly, the obtained precipitate was dried at room temperature. To prepare the $\mathrm{ZnO}$ nanogel, the produced $\mathrm{ZnO}$ NPs were rinsed with double deionized water and were outfitted for the next step. On the other hand, $0.5 \mathrm{~g}$ of Carbopol 940 (Loba Chemie, Mumbai, India) was dissolved in $300 \mathrm{~mL}$ of doubled deionized water, followed by addition of the freshly washed ZnO NPs. Because Carbopol is naturally acidic [55], the solution needed to be neutral, otherwise it would not thicken. Thus, the mixture had undergone continuous sonication using an ultrasound prop (Hielscher, UP400S Berlin, Germany) with an amplitude of 95 and a cycle of $95 \%$ for $1 \mathrm{~h}$. Then, $50 \mathrm{~mL}$ of trimethylamine (TEA) as a neutralizing agent (raise the $\mathrm{pH}$ to 7) was added dropwise under continuous sonication until the formation of the $\mathrm{ZnO}$ white gel occurred, and where the Carbopol would thicken when the $\mathrm{pH}$ was near to the neutral conditions [56]. Figure 1 shows a summarized schematic flowchart of the synthesis procedures for the ZnO NPs as well as the Carbopol/ZnO hybrid nanoparticles gel.

\subsection{Characterization of Synthesized ZnO NPs and Carbopol/ZnO Hybrid Nanoparticles Gel}

The synthesized ZnO NPs and Carbopol/ZnO hybrid nanoparticles gel were investigated for determining the chemical composition and the crystalline phase using an X-ray diffractometer (XRD, D8-Discover, Bruker, $\mathrm{CuK} \alpha$ radiation, Madison, WI, USA) working at a current of $30 \mathrm{~mA}$ and voltage of $20 \mathrm{kV}$. The Raman shift spectrum of the synthesized ZnO NPs and Carbopol/ZnO hybrid nanoparticles gel were investigated using the Raman spectrometer of a model (Horiba labRAM HR evolution visible single spectrometer, Edison, NJ, USA). The measurement processes were performed at room temperature and the acquisition time was 20 seconds. The Raman spectroscopy was supplied with a He-Cd green LASER which provided a wavelength of $532 \mathrm{~nm} /$ edge, and a grating of 1800 (450-850 nm), supported with a $100 \%$ ND filter and an objective of X50/Vis. The scanning electron microscope (SEM, JSM-6701F Plus, JEOL, Peabody, MA, USA), and transmission electron microscope (JEOL, TEM-2100, Peabody, MA, USA) operated at a potential of $20 \mathrm{kV}$, and were used to investigate the morphology, shape, and size of the Carbopol/ZnO hybrid nanoparticles gel. In the investigations of the samples using TEM, a copper grid was prepared to support the NPs by sputtering them with gold. The ZnO NPs stabilized Carbopol gel sample was diluted with distilled water and sonicated with an ultrasonic cleaner (Elma, Singen, Germany) for $30 \mathrm{~min}$. Then, a few drops of the Carbopol/ZnO hybrid nanoparticles gel sample were deposited onto the coated copper grid and allowed to dry at room temperature before the investigations were performed by the TEM microscopy. The specific surface area of the Carbopol/ZnO hybrid nanoparticles gel sample was determined by the $\mathrm{N}_{2}$ adsorption/desorption isotherm using Brunauer-Emmett Teller (BET) 
analyzer (NOVA touch LX2, model; NT2LX-2, Quantachrome, FL, USA). An Atomic Force Microscope (AFM, 5600LS, Agilent, California, CA, USA) was used to provide 2D and 3D topographic images of the synthesized Carbopol/ZnO hybrid nanoparticles gel. Finally, the particle size and zeta potential of the prepared ZnO NPs and Carbopol/ZnO hybrid nanoparticles gel samples were measured using a DLS and zeta potential analyzer (Nano Sight NS500, Malvern Instruments Ltd., Kassel, Germany).

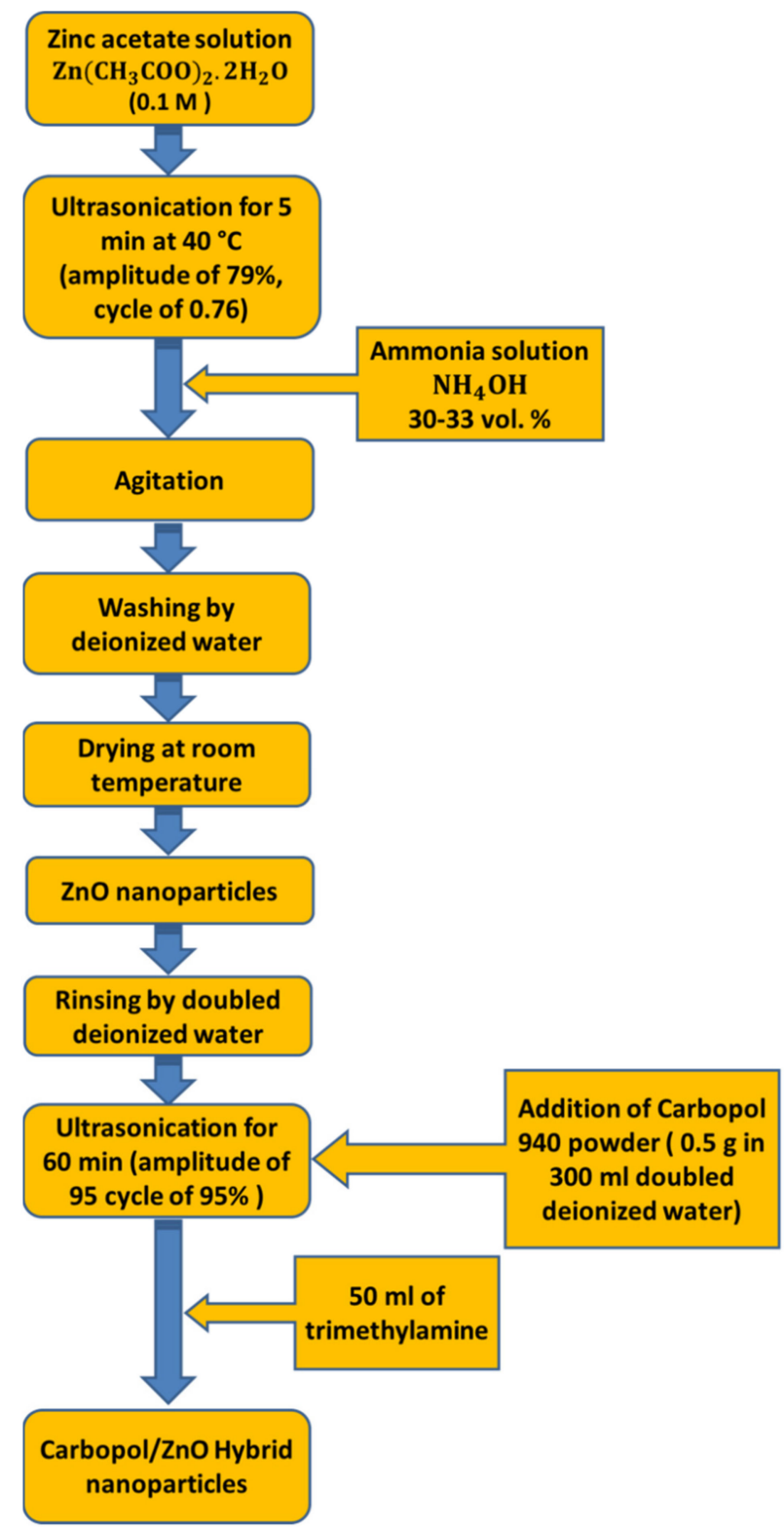

Figure 1. Schematic flowchart for the synthesis of ZnO NPs and Carbopol/ZnO hybrid nanoparticles gel.

\subsection{Antibacterial Sensitivity Test}

The antibacterial activity of the investigated Carbopol/ZnO hybrid nanoparticles gel was employed on Mueller-Hinton agar plates using an Agar well diffusion technique against gram-negative K. pneumonia (ATCC 13883) and gram-positive Bacillus subtilis (ATCC 6633), and Staphylococcus aureus (ATCC 6538) bacterial strains, and by applying ampicillin as a reference antibacterial agent. A stock solution was prepared by dissolving $10 \mathrm{mg}$ of Carbopol/ZnO hybrid nanoparticles gel in $1 \mathrm{~mL}$ DMSO. The nutrient agar medium of the composition (0.5\% Peptone, $0.1 \%$ Beef extract, $0.2 \%$ Yeast extract, $0.5 \% \mathrm{NaCl}$, and $1.5 \%$ 
Agar-Agar) was prepared by heating the contents in a water bath, cooling them down to $47^{\circ} \mathrm{C}$, and seeding them with the investigated microorganisms. After the solidification of the Agar media, $5 \mathrm{~mm}$ diameter holes were punched aseptically and carefully using a sterile cork borer. The investigated Carbopol/ZnO hybrid nanoparticles gel was introduced in Petri-dishes (10 cm diameter) after their dissolving in DMSO to reach a $1.0 \times 10^{-3} \mathrm{M}$ concentration. The prepared culture plates were then incubated at $37^{\circ} \mathrm{C}$ for $20 \mathrm{~h}$ to enhance the growth of the bacteria. The activity was determined by measuring the diameter of the inhibition zone in $\mathrm{mm}$. The plates were kept for incubation at $37^{\circ} \mathrm{C}$ for $24 \mathrm{~h}$ and then the plates were investigated for a recording of the zone of inhibition in millimeters. Antimicrobial activities were performed in triplicate and the average was taken as the final reading.

\section{Results and Discussion}

\subsection{Synthesis and Stabilization Mechanism of $\mathrm{ZnO} N P$ s by Carbopol Gel}

The consequence chemical precipitation reactions of the synthesis method of ZnO NPs, as well as the Carbopol/ZnO hybrid nanoparticles gel, can be explained by the following chemical equations;

$$
\begin{aligned}
& \mathrm{Zn}\left(\mathrm{CH}_{3} \mathrm{COO}\right)_{2} \cdot 2 \mathrm{H}_{2} \mathrm{O}+2 \mathrm{NH}_{4} \mathrm{OH} \rightarrow \mathrm{Zn}(\mathrm{OH})_{2}+2 \mathrm{CH}_{3} \mathrm{COONH}_{4}+2 \mathrm{H}_{2} \mathrm{O} \\
& \mathrm{Zn}(\mathrm{OH})_{2}+2 \mathrm{H}_{2} \mathrm{O} \rightarrow \mathrm{Zn}^{2+}+2 \mathrm{HO}^{-}=\left[\mathrm{Zn}(\mathrm{OH})_{4}\right]^{2-} \\
& {\left[\mathrm{Zn}(\mathrm{OH})_{4}\right]^{2-} \leftrightarrow \mathrm{ZnO}_{2}^{2-}+2 \mathrm{H}_{2} \mathrm{O}} \\
& \mathrm{ZnO}_{2}^{2-} \stackrel{24 \mathrm{kHz}, 400 \mathrm{~W}, \Delta}{\longrightarrow} \mathrm{ZnO} \downarrow+\mathrm{O}_{2} \uparrow
\end{aligned}
$$

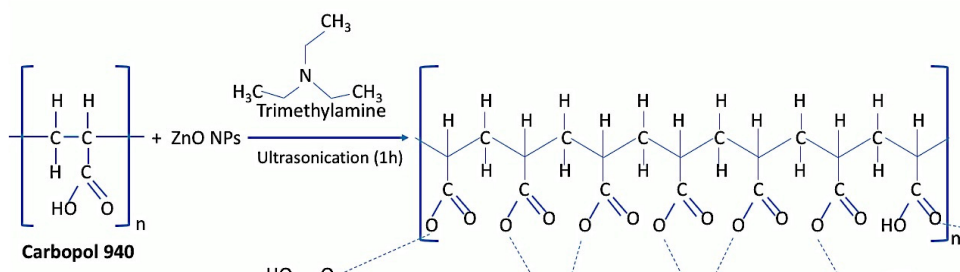

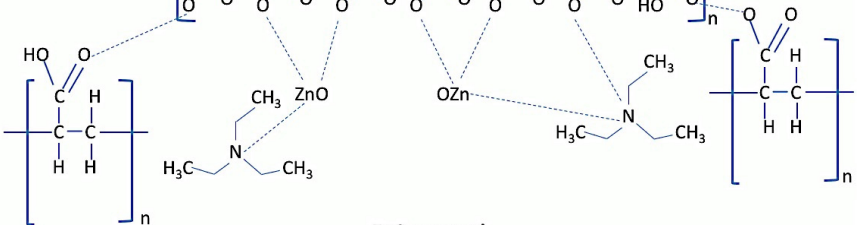

$$
\begin{aligned}
& \text { ZnO nano-gel }
\end{aligned}
$$

According to the chemical equations mentioned above, (Equation (1) to Equation (4), the zinc acetate reacted with an equivalent amount of ammonium hydroxide solution forming zinc hydroxide precipitate, which dissolved to form ammonium zincate in the presence of an excess amount of ammonium hydroxide solution. The formed ammonium zincate was converted into $\mathrm{ZnO}$ nanoparticles by heating under the effect of ultrasonic wave irradiation. The produced $\mathrm{ZnO}$ NPs were stabilized by the interaction with Carbopol according to the chemical Equation (5). The Carbopol gel is usually formed by adding the Carbopol powder to distilled water, which was previously neutralized to $\mathrm{pH}=7$ using few drops of inorganic bases, such as sodium hydroxide or potassium hydroxide, or low molecular weight amines and alkanolamines, which can provide satisfactory neutralization. Some of the amine bases that are effective as neutralizing agents for aqueous formulations include TEA (triethanolamine), AMP-95 (aminomethyl propanol), Tris Amino (tromethamine), and Neutrol TE (tetrakis-2-hydroxypropyl ethylenediamine) [57-59]. Then, the obtained mixture was subjected to continuous rigorous mixing for a few minutes to avoid agglomeration, and then continued stirring until viscosity built up before it turned to gel. In the current work, and according to Equation (5), trimethylamine was used as a neutralizing agent to produce a matrix gel between $\mathrm{ZnO}$ NPs and the Carbopol network. The Carbopol/ZnO hybrid nanoparticles gel is formed by the agitation of the ZnO NPs within Carbopol solution to 
achieve the homogeneity of mixture and to facilitate the polymer-solvent and polymerpolymer interactions giving rise to a better-network structure, typically of a gel-like system. Besides, adding the neutralizing agent induces the entanglement between the different polymer chains. The neutralization reaction ionizes the polymer and generates negative charges along the chain of the polymer. The repulsions between similar charges cause the uncoiling of the molecule into an extended strained structure. This reaction occurs rapidly and provides an instantaneous thickening and an emulsion formation/stabilization. Consequently, the mixture starts to convert to the Carbopol gel network and chelates with the ZnO NPs inside its chain structure. The thick structure and higher elastic character of the hydrated Carbopol/ZnO hybrid nanoparticles gel may be attributed to the electrostatic, Vander Walls, dipole-dipole, hydrophobic type interactions, and the formation of H-bonding, which can be established between ZnO NPs and the hydroxyl groups of Carbopol base-polymer due to the high electronegativity of the oxygen atom. Moreover, there is a possibility for H-bonding creation between $\mathrm{ZnO}$ NPs and the nitrogen atoms of trimethylamine agents, even though it has a lower electronegativity than that of the oxygen atom. Furthermore, ultrasonic wave irradiation causes particle-particle interaction by enhancing the molecular vibration of the constituent in the reaction mixture, which generally enhances the thickening process promoted by the polymer-solvent interactions, and aids in the solvation of Carbopol. In addition, ultrasound wave irradiation enhances the polymer-ZnO NPs interaction and improves the viscoelastic properties of the prepared Carbopol/ZnO hybrid nanoparticles gel. Accordingly, many studies have introduced similar interpretations [60-64].

Figure 2 shows the prepared $\mathrm{ZnO}$ NPs as well as the Carbopol/ZnO hybrid nanoparticles gel. The results indicate that the prepared ZnO NPs, in the absence of any stabilizing agent, were partially suspended and settled down in the solution within a short period. However, the Carbopol/ZnO hybrid nanoparticles gel was completely suspended and did not settle down for a long time, eventually forming a homogeneous gel. Therefore, one can see that Carbopol is a suitable stabilizing agent for the ZnO NPs in the solution.

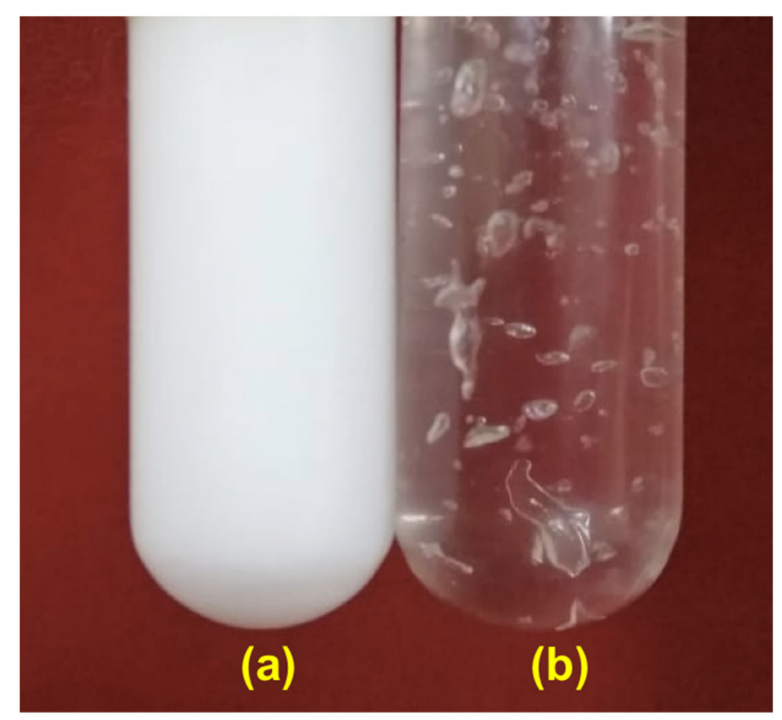

Figure 2. ZnO NPs synthesized by the chemical precipitation method under the effect of the ultrasound wave irradiation, where (a) is in the aqueous solution, and (b) is stabilized by Carbopol gel.

3.2. Chemical Composition and Phase Identification of Synthesized $\mathrm{ZnO} N P s$ and Carbopol/ZnO Hybrid Nanoparticles Gel

Figure 3 shows the XRD pattern of the synthesized ZnO NPs and Carbopol/ZnO hybrid nanoparticles gel. It can be observed from the results that the diffraction peaks have a high intensity, which implies an ideal crystalline structure within the synthesized $\mathrm{ZnO}$ NPs. The Carbopol gel is in an amorphous state as no peaks were recorded. Besides, 
the characteristic peaks of zinc oxide are prominently featured in the XRD pattern of the Carbopol/ZnO hybrid nanoparticles gel. In addition, the crystalline structure of the synthesized $\mathrm{ZnO}$ NPs demonstrates a hexagonal structure of the high-purity $\mathrm{ZnO}$ wurtzite phase according to the reference COD no. 2300113. Thus, the observed peaks corresponding to the (100), (002), (101), (102), (110), (103), (200), (112), (201), (004) and (202) planes. Furthermore, the $\mathrm{Zn}$ element represents $80.3 \%$, while the oxygen element represents $19.7 \%$ of the sample. The average crystallite size (D) of ZnO NPs was estimated from the highly intense and sharp diffraction peak corresponding to the (101) plane using the Debye-Scherer formula [65] according to the following equation:

$$
\mathrm{D}=\frac{0.9 \lambda}{\beta \cos \theta}
$$

where $\mathrm{D}$ is the average crystalline size $(\mathrm{nm}), \lambda$ the $\mathrm{CuK} \alpha$ radiation wavelength, i.e., $1.54060 \AA, \beta$ the full-width at half maximum in radians, and $\theta$ the scattering angle in degree. The average crystallite size of the synthesized $\mathrm{ZnO}$ nanoparticle was found to be $48.70 \mathrm{~nm}$. Similar results were reported in the previous work [66]. The assessment of different diffraction peaks and the detailed XRD analysis of ZnO NPs and Carbopol/ZnO hybrid nanoparticles gel are listed in Table 1.

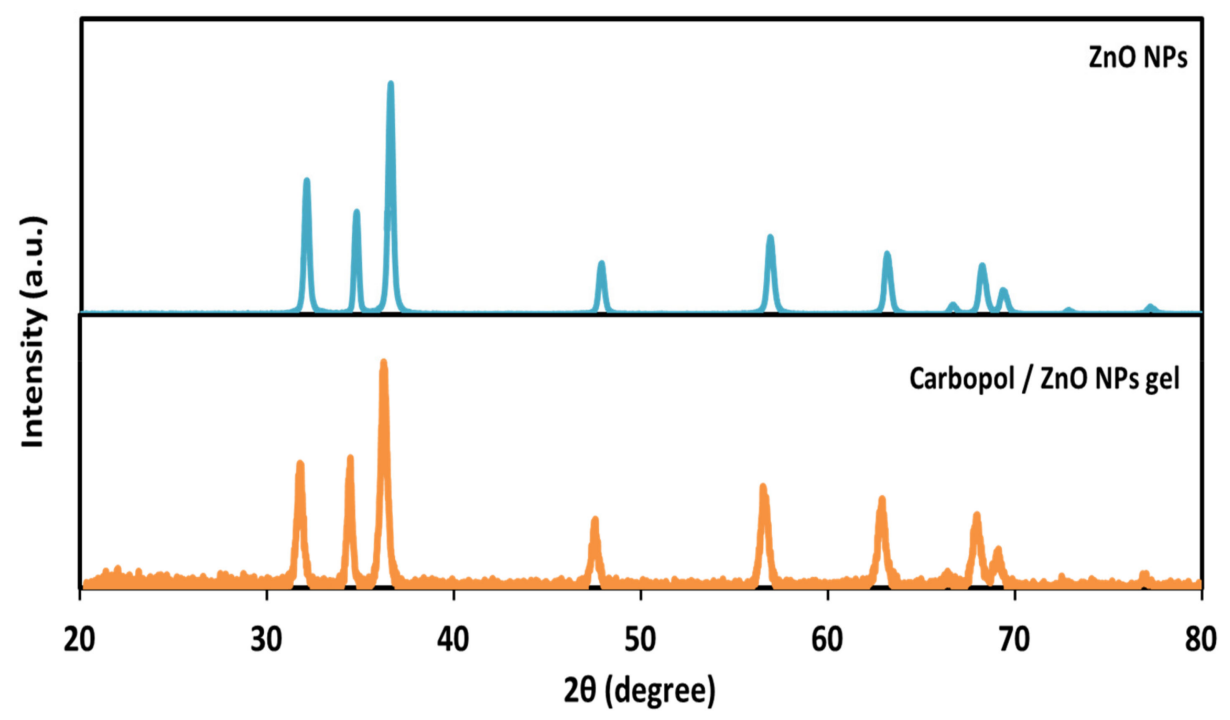

Figure 3. XRD patterns of the synthesized ZnO NPs and Carbopol/ZnO hybrid nanoparticles gel.

Table 1. Appraised parameters of the XRD analysis of synthesized ZnO NPs and Carbopol/ZnO hybrid nanoparticles gel.

\begin{tabular}{|c|c|c|c|c|c|c|}
\hline \multirow[b]{2}{*}{ Index } & \multirow[b]{2}{*}{ d-Value (Å) } & \multicolumn{2}{|c|}{ ZnO NPs } & \multicolumn{3}{|c|}{ Carbopol/ZnO Hybrid Nanoparticles Gel } \\
\hline & & $2 \theta\left({ }^{\circ}\right)$ & hkl & d-Value ( $)$ & $2 \theta\left({ }^{\circ}\right)$ & hkl \\
\hline 1 & 2.8009 & 31.926 & 100 & 2.8141 & 31.773 & 100 \\
\hline 2 & 2.5886 & 34.624 & 002 & 2.6027 & 34.430 & 002 \\
\hline 3 & 2.4635 & 36.442 & 101 & 2.4755 & 36.259 & 101 \\
\hline 4 & 1.901 & 47.808 & 102 & 1.9107 & 47.551 & 102 \\
\hline 5 & 1.6171 & 56.894 & 210 & 1.6247 & 56.604 & 210 \\
\hline 6 & 1.4692 & 63.242 & 103 & 1.4769 & 62.875 & 103 \\
\hline 7 & 1.4004 & 66.742 & 200 & 1.4070 & 66.388 & 200 \\
\hline 8 & 1.3715 & 68.34 & 212 & 1.3782 & 67.962 & 212 \\
\hline 9 & 1.3519 & 69.471 & 201 & 1.3583 & 69.097 & 201 \\
\hline 10 & 1.2943 & 73.046 & 004 & 1.3013 & 72.591 & 004 \\
\hline 11 & 1.2317 & 77.422 & 202 & 1.2377 & 76.978 & 202 \\
\hline
\end{tabular}


Based on the aforementioned results, and in comparison with previous studies, the existence of ZnO NPs in the hexagonal wurtzite structure demonstrated a high purity and an excellent crystallinity in the synthesized particles. Table 2 shows the crystallinity and phase structures of $\mathrm{ZnO}$ NPs prepared using different methods.

Table 2. Crystallinity of synthesized ZnO NPs based on the synthesis route and structure compared with those in the literature.

\begin{tabular}{|c|c|c|c|c|}
\hline Synthesis Route & Crystal Phase & Lattice Structure & Crystallite Size (nm) & References \\
\hline Green synthesis by sheep and goat fecal matter & Hexagonal & Wurtzite & 28.50 & [67] \\
\hline Biological synthesis of $\mathrm{ZnO}$ NPs using C. albicans & Hexagonal & Wurtzite & 25.00 & [68] \\
\hline $\begin{array}{l}\text { Biogenic synthesis of } \mathrm{ZnO} \text { NPs using an aqueous } \\
\text { extract of Papaver somniferum L }\end{array}$ & Hexagonal & Wurtzite & 48.00 & [69] \\
\hline $\begin{array}{l}\text { ZnO NPs synthesized via a solvothermal method } \\
\text { in triethanolamine (TEA) media }\end{array}$ & Hexagonal & Wurtzite & 33.00 & {$[70]$} \\
\hline $\begin{array}{l}\text { Hydrothermal synthesis of highly crystalline } \\
\text { ZnO NPs }\end{array}$ & Hexagonal & Wurtzite & 17.00 & {$[71]$} \\
\hline $\begin{array}{l}\text { Sol-gel synthesis of ZnO NPs at three different } \\
\text { calcination temperatures }\end{array}$ & Hexagonal & Wurtzite & 30.00 & {$[72]$} \\
\hline $\begin{array}{c}\text { Chemical precipitation/ultrasonication synthesis } \\
\text { of ZnO NPs }\end{array}$ & Hexagonal & Wurtzite & 48.70 & This study \\
\hline
\end{tabular}

As shown in Table 2, most of the studies in the literature reported a similar crystallite size for ZnO NPs, although prepared by different methods, and confirmed the same lattice structure.

\subsection{Raman Spectrum of the Synthesized ZnO NPs and Carbopol/ZnO Hybrid Nanoparticles Gel}

The Raman spectrum is a fundamental and multilateral diagnostic technique that can be used to investigate the structural disorder, crystallization, and defects in the micro and nanostructures materials. The vibrational modes of the synthesized ZnO NPs and Carbopol/ZnO hybrid nanoparticles gel are studied. The ZnO NPs of hexagonal wurtzite crystal-type structures belong to the space group of $\mathrm{P} 63_{\mathrm{mc}}$ with two formula units per primitive cell. Also, for pure ZnO NPs crystals, the optical phonons at $\Gamma_{\text {opt }}$ point of the Brillouin zone are included in a first-order Raman scattering. According to the classical group theory, the zone center optical phonons can be assorted according to the following irreducible equation:

$$
\Gamma_{\text {opt }}=\mathrm{A}_{1}+2 \mathrm{~B}_{2}+\mathrm{E}_{1}+2 \mathrm{E}_{2}
$$

where both the $A_{1}$ and $E_{1}$ modes are two polar branches and both are Raman and infrared active. Due to the macroscopic electric fields associated with the LO phonons, the two modes are divided into transversal optical (TO) and longitudinal optical (LO) branches with various frequencies. Otherwise, the $A_{1}, E_{1}$, and $E_{2}$ modes $\left(E_{2}\right.$ low and $E_{2}$ high) are non-polar and first-order Raman-active modes, where the $\mathrm{E}_{2}$ modes are only active for Raman-shift. As shown in Figure 4, the main phonon scattering modes of the $\mathrm{ZnO}$ NPs have recorded two bands at 58.05 and $473.87 \mathrm{~cm}^{-1}$ that attributed to the 2nd order Raman scattering arising from the $\mathrm{E}_{2 \mathrm{~L}}$ and $\mathrm{E}_{2 \mathrm{H}}$ vibrational modes. The broad mode centered at $515.64 \mathrm{~cm}^{-1}$ is assigned to the $\mathrm{E}_{1}(\mathrm{LO})$ mode, which is defects induced: oxygen vacancies and zinc interstitials. Whereas, the main phonon scattering modes of the Carbopol/ZnO hybrid nanoparticles gel were recorded in eight bands at 59.80, 553.93, $1097.21,1455.96,1638.38,2411.25,2543.44$, and $2940.24 \mathrm{~cm}^{-1}$, which corresponds to the $\mathrm{E}_{2 \mathrm{~L}}$, $\mathrm{E}_{2 \mathrm{H}}, \mathrm{A}_{1}(\mathrm{LO}) / \mathrm{E}_{1}(\mathrm{LO}), \mathrm{C}-\mathrm{O}$ stretch, $\mathrm{O}-\mathrm{C}-\mathrm{O}$ bend, $\mathrm{CH}_{3}$ bend, $\mathrm{CH}_{3}$ stretch, and $\mathrm{NH}$ stretch modes, respectively, while, the second-order phonon mode recorded at about $178.58 \mathrm{~cm}^{-1}$ is represented as $2 \mathrm{E}_{2 \mathrm{~L}}$, and the $\mathrm{E}_{2 \mathrm{H}}$ Raman mode observed at $553.93 \mathrm{~cm}^{-1}$ is dominantly attributed to the oxygen vibrations. On the other hand, according to the Raman selection 
rule, the $B_{1}$ modes are usually inactive in Raman spectra and are identified as silent modes. The multi phonon scattering modes are recorded at $464.59,769.87$, and $953.89 \mathrm{~cm}^{-1}$, which may be assigned to $3 \mathrm{E}_{2 \mathrm{H}}-\mathrm{E}_{2 \mathrm{~L}}, 2\left(\mathrm{E}_{2 \mathrm{H}}-\mathrm{E}_{2 \mathrm{~L}}\right)$, and $\mathrm{A}_{1}(\mathrm{TO})+\mathrm{E}_{1}(\mathrm{TO})+\mathrm{E}_{2 \mathrm{~L}}$, respectively. In addition, an acoustic combination of $A_{1}$ and $E_{2}$ is recorded at around $953.89 \mathrm{~cm}^{-1}$. Moreover, the Raman spectra can help in identifying the chemical forms of the Carbopol ligands, as the vibration frequencies of the functional groups are sensitive to the chemical environment. The other vibrational bands were observed in the Raman spectrum at 1455.96, $1638.38,2411.25$, and $2543.44 \mathrm{~cm}^{-1}$, and could be originated from Carbopol ligand groups attached to the $\mathrm{ZnO}$ NPs' surfaces. However, the $\mathrm{C}-\mathrm{O}$ stretch, $\mathrm{O}-\mathrm{C}-\mathrm{O}$ bend, $\mathrm{CH}_{3}$ bend, $\mathrm{CH}_{3}$ stretch, and $\mathrm{NH}$ stretch modes are much more sensitive to the surrounding environment. It could be stated the Raman shift spectrum for Carbopol gel exhibited the same vibrational modes of $\mathrm{ZnO}$ NPs besides the vibrational, rotational, and other low-frequency modes of the hybrid system, causing the multi-phonon to shift to higher wavenumbers. In addition, the structural fingerprint for both ZnO NPs and Carbopol gel were identified. Diallo et al. have mentioned similar vibrational properties of ZnO NPs synthesized by Aspalathus linearis [73]. Moreover, Muchuweni et al. have mentioned similar results for the Raman shift of $\mathrm{ZnO}$ nanowires prepared using a hydrothermal method [74]. In addition, Taziwa et al. have presented the Raman spectra for both unmodified $\mathrm{ZnO}$ and $\mathrm{C}: \mathrm{ZnO}$ NPs synthesized using the PSP technique. They found that the C:ZnO NPs recorded a red-shift by $4 \mathrm{~cm}^{-1}$ compared to that found in bulk $\mathrm{ZnO}$ samples. They attributed this shift either to the phonon confinement and tensile stress within the nanocrystal (quantum dots) boundaries, or the localization of phonons inside the C:ZnO NPs hybrid system, which has a more inherent defect when compared to pristine ZnO NPs [75]. On the contrary, in a study by Jayachandraiah and Krishnaiah, both reported that the main phonon scattering modes of Er-doped ZnO NPs systems dropped with different Er ratios without a significant shift [76].

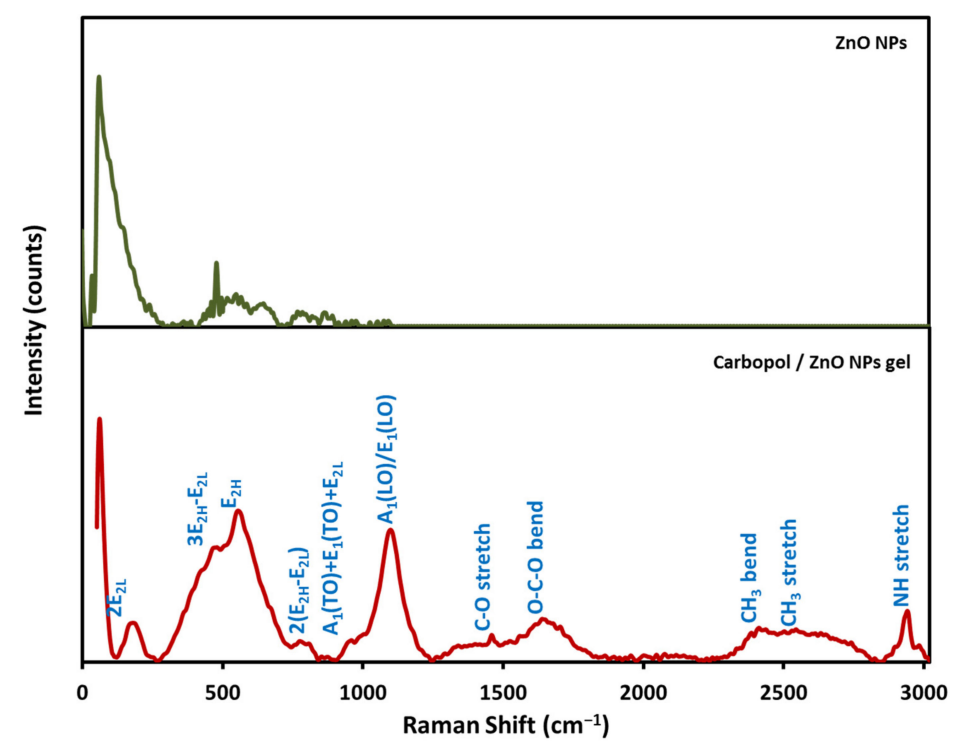

Figure 4. Raman shift spectrums of the synthesized ZnO NPs and Carbopol/ZnO hybrid nanoparticles gel.

\subsection{BET Surface Area and Pore Size Distribution Analysis of the Synthesized Carbopol/ZnO Hybrid Nanoparticles Gel}

The specific surface area of the synthesized Carbopol/ZnO hybrid nanoparticles gel was determined using the $\mathrm{N}_{2}$ adsorption/desorption isotherm at a temperature of $77 \mathrm{~K}$. Figure 5 shows the typical IV-type adsorption of the Carbopol/ZnO hybrid nanoparticles. Usually, the mesoporous adsorbents are exhibiting type IV isotherms (e.g., mesoporous molecular sieves, industrial adsorbents, and many oxide gels). In this case, the interactions between the molecules in the condensed state, and the adsorbent/adsorptive interactions, 
were designated to determine adsorption behavior in the mesoporous materials. Based on this reason, the initial monolayer-multilayer adsorption occurring on the mesoporous walls was followed by pore condensation. The phenomenon of pore condensation means that, at a pressure $p$ less than the saturation pressure $p_{o}$ of the bulk liquid, the gas condenses to a liquid-like phase in the pores [77]. According to the characteristics of the IV type, the capillary condensation taking place in mesoporous may be accompanied by hysteresis, which commonly occurs when the pore size exceeds a certain critical width. It could be said that the capillary condensation depends mainly on the adsorption system and temperature (for nitrogen adsorption in cylindrical pores at $77 \mathrm{~K}$ ). Furthermore, as shown in the isotherm curve in Figure 4, the isotherm did not contain a hysteresis loop that starts to occur when the pores of the adsorbent are wider than $\sim 4 \mathrm{~nm}$. Consequently, the specific surface area of Carbopol/ZnO hybrid nanoparticles gel was determined at $54.26 \mathrm{~m}^{2} / \mathrm{g}$, while the pore volume and the mean pore diameter were found to be $0.063 \mathrm{~cm}^{3} / \mathrm{g}$ and $2.33 \mathrm{~nm}$, respectively. The BET results of the Carbopol/ZnO hybrid nanoparticles gel are listed in Table 3. Kołodziejczak-Radzimska et al. reported similar results in their analysis [78].

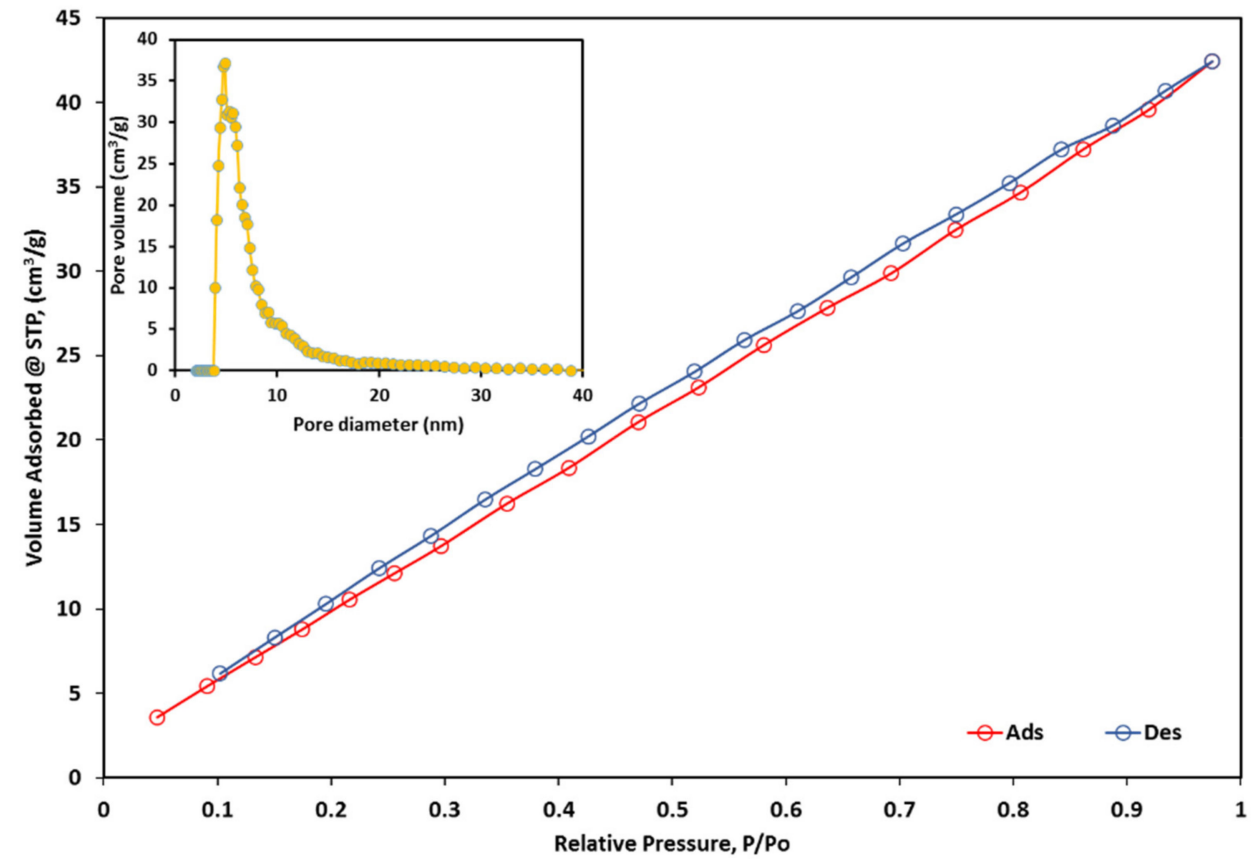

Figure 5. $\mathrm{N}_{2}$ gas adsorption/desorption isotherm of the synthesized Carbopol/ZnO hybrid nanoparticles gel.

Table 3. BET parameters of the synthesized Carbopol/ZnO hybrid nanoparticles gel.

\begin{tabular}{cc}
\hline \multicolumn{2}{c}{ Carbopol Stabilized ZnO NPs } \\
\hline BET surface area, $\mathrm{m}^{2} / \mathrm{g}$ & 54.26 \\
Average particle size, $\mathrm{nm}$ & 5.02 \\
Mean pore diameter, $\mathrm{nm}$ & 2.33 \\
Total pore volume, $\mathrm{cm}^{3} / \mathrm{g}$ & 0.063 \\
\hline
\end{tabular}

As shown in Table 4, the Carbopol/ZnO hybrid nanoparticles gel exhibited a relatively high surface area when compared with the bare ZnO NPs and some other hybrid systems. Accordingly, this demonstrates that the Carbopol gel provided an extra area for ZnO NPs to disperse, and subsequently contributed to increasing the overall surface area of the obtained sample. As presented in Table 3, and as stated by the different reports, all hybrid systems showed higher surface areas than those of bare metal oxides. 
Table 4. Comparison of the obtained SBET of synthesized Carbopol/ZnO hybrid nanoparticles gel with those for bare ZnO NPs and the other hybrid systems in the literature.

\begin{tabular}{|c|c|c|}
\hline Materials & $\mathrm{S}_{\mathrm{BET}}, \mathrm{m}^{2} / \mathrm{g}$ & References \\
\hline $\begin{array}{l}\text { Bare } \mathrm{ZnO} \mathrm{NPs} \\
\mathrm{Pd}-\mathrm{ZnO}-\mathrm{EG}\end{array}$ & $\begin{array}{l}3.29 \\
4.93\end{array}$ & [79] \\
\hline $\begin{array}{c}\text { ZnO precursor } \\
\text { ZnO Xerogel nanostructers annealed at } \\
275^{\circ} \mathrm{C} \\
375^{\circ} \mathrm{C} \\
475^{\circ} \mathrm{C} \\
600^{\circ} \mathrm{C}\end{array}$ & $\begin{array}{l}87.43 \\
25.36 \\
22.81 \\
15.16 \\
8.78\end{array}$ & {$[80]$} \\
\hline $\begin{array}{l}\text { ZnO nanostructures modified chitosan and sodium chloroacetate } \\
\text { with isopropyl alcohol } \\
\text { ZnO-CTS-450 } \\
\text { ZnO-CMC1-450 } \\
\text { ZnO-CTS-650 } \\
\text { ZnO-CMC1-650 }\end{array}$ & $\begin{array}{c}23.76 \\
15.44 \\
11.92 \\
5.88\end{array}$ & [81] \\
\hline $\begin{array}{l}\text { Modified ZnO NPs } \\
\mathrm{Ag} / \mathrm{ZnO} \mathrm{NPs} \\
\mathrm{Cd} / \mathrm{ZnO} \mathrm{NPs} \\
\mathrm{Pb} / \mathrm{ZnO} \mathrm{NPs}\end{array}$ & $\begin{array}{c}7.75 \\
10.6 \\
106.65\end{array}$ & [82] \\
\hline $\begin{array}{c}\text { ZnO synthesized without any biotemplate } \\
\mathrm{ZnO} \text { synthesized at different volumes of palm olein } \\
1 \mathrm{~mL} \mathrm{PO} \\
2 \mathrm{~mL} \mathrm{PO}\end{array}$ & $\begin{array}{l}5 \\
10 \\
13\end{array}$ & {$[83]$} \\
\hline Kaolin/ZnO nanocomposites & 31.8 & {$[84]$} \\
\hline $\begin{array}{l}\text { Gum arabic-crosslinked-poly(acrylamide)/zinc oxide hydrogels } \\
\text { (GA-cl-PAM/ZnO hydrogel) }\end{array}$ & 39.0 & {$[85]$} \\
\hline Flower-like ZnO NPs in a cellulose hydrogel microreactor & 39.18 & [86] \\
\hline $\begin{array}{l}\mathrm{ZnO} / \mathrm{PAAH} \text { hybrid nanomaterials }(\mathrm{PAAH}=\text { polyacrylic acid) } \\
\qquad \mathrm{ZnO} / \mathrm{PAA} 2-350^{\circ} \mathrm{C} \\
\mathrm{ZnO} / \mathrm{PAA} 5-350^{\circ} \mathrm{C}\end{array}$ & $\begin{array}{l}51 \\
31\end{array}$ & [87] \\
\hline Carbopol/ZnO hybrid nanoparticles gel & 54.26 & This study \\
\hline Alginate/ $\mathrm{Zn}$ aerogel beads & 143 & {$[88]$} \\
\hline Highly dispersed ZnO NPs supported on the silica gel matrix & 245 & [89] \\
\hline Cellulose/ZnO hybrid aerogel (CA/ZnO) & 352.82 & {$[90]$} \\
\hline Wheat gliadin/ZnO hybrid nanospheres & 523.88 & [91] \\
\hline
\end{tabular}

\subsection{AFM Topographical Analysis of the Synthesized Carbopol/ZnO Hybrid Nanoparticles Gel}

Figure 6a-d shows the non-contact mode topographical AFM 2D images and the corresponding 3D images for the synthesized Carbopol/ZnO hybrid nanoparticles gel. The images demonstrated that the Carbopol/ZnO hybrid nanoparticles have a spherical particle shape. In addition, a good distribution and monodisperse of a large number of random nano pits are observed. Furthermore, the automated batch-mode particleheight functional analysis provided a corresponding particle size distribution histogram of the synthesized Carbopol/ZnO hybrid nanoparticles gel through the scanned area, whereas the synthesized Carbopol/ZnO hybrid nanoparticles gel exhibited a homogeneous particle size of normal distribution. Moreover, the maximum peak height was found to be $59.9 \mathrm{~nm}$, which represents the average particle size of synthesized Carbopol/ZnO hybrid nanoparticles gel, as shown in Figure 6e,f. Furthermore, the corresponding particle volume distribution histogram showed that the volume of the Carbopol/ZnO hybrid nanoparticles gel was found to be $0.0113\left(\mathrm{~V} \cdot \mu \mathrm{m}^{2} / \mu \mathrm{m}^{2}\right)$, and the volume of the void per cross-sectional area was $0.206\left(\mathrm{~V} . \mu \mathrm{m}^{2} / \mu \mathrm{m}^{2}\right)$ as presented in Figure $6 \mathrm{~g}, \mathrm{~h}$. Similar results were reported in previous studies [92]. Moreover, the results of the AFM are correlative with the results of the XRD. 
(a)

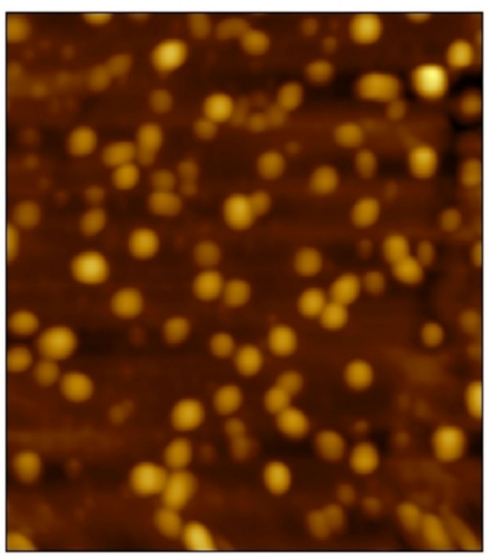

(c)

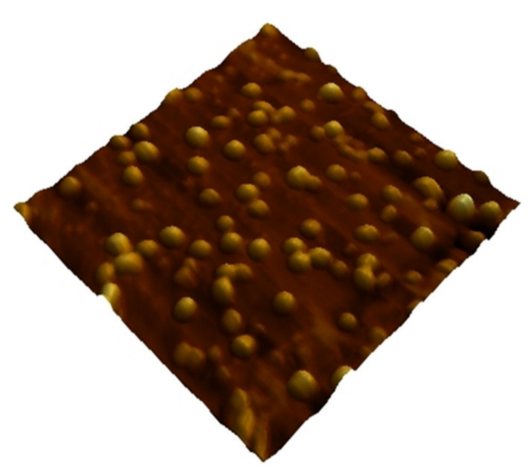

(e)

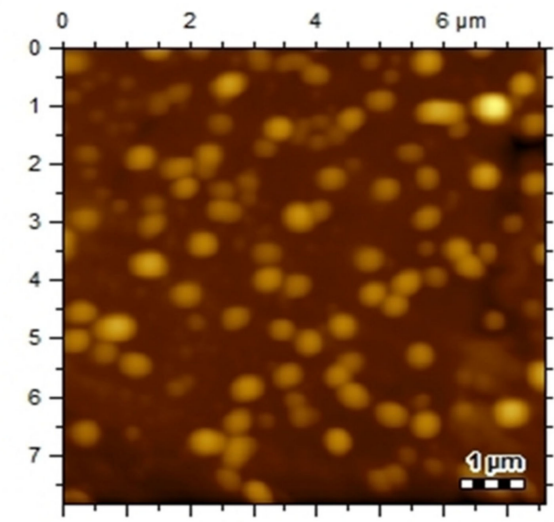

$\mu \mathrm{m}$

(g)

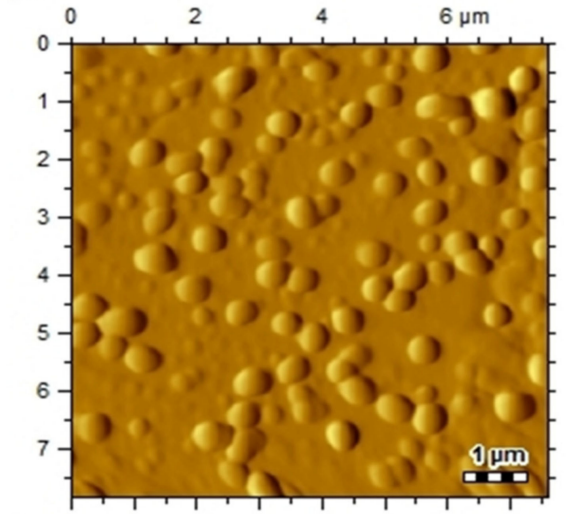

$\mu \mathrm{m}$ nm (b)

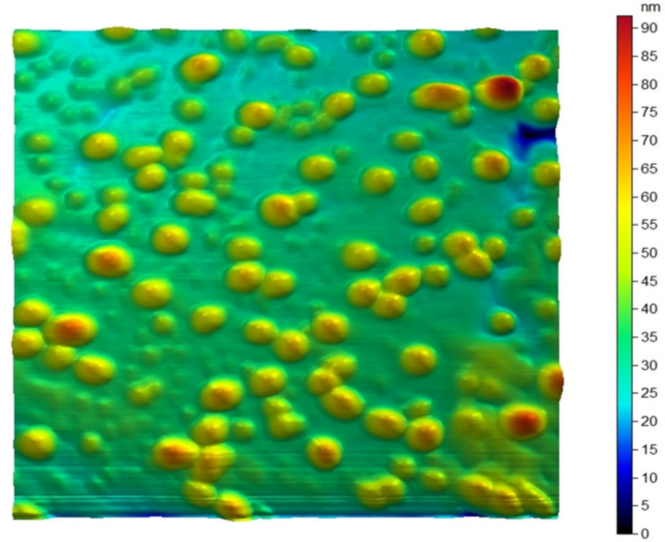

(d)

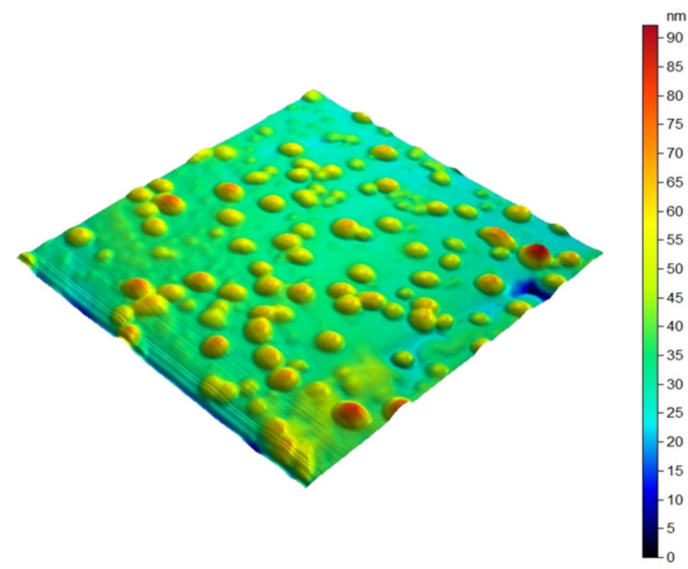

(f)

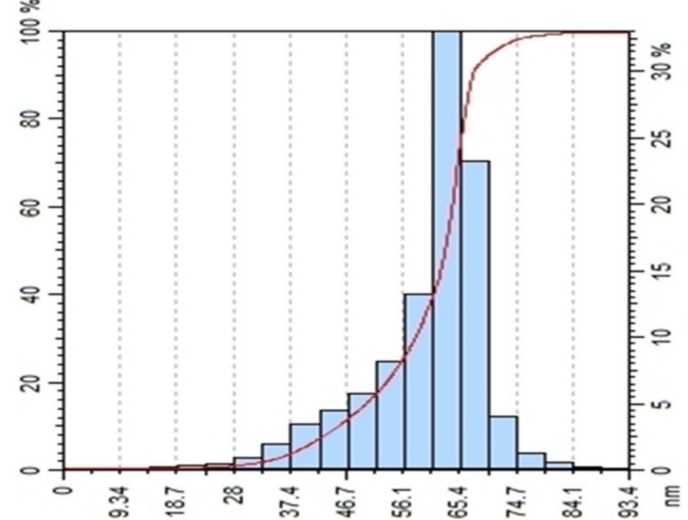

(h)

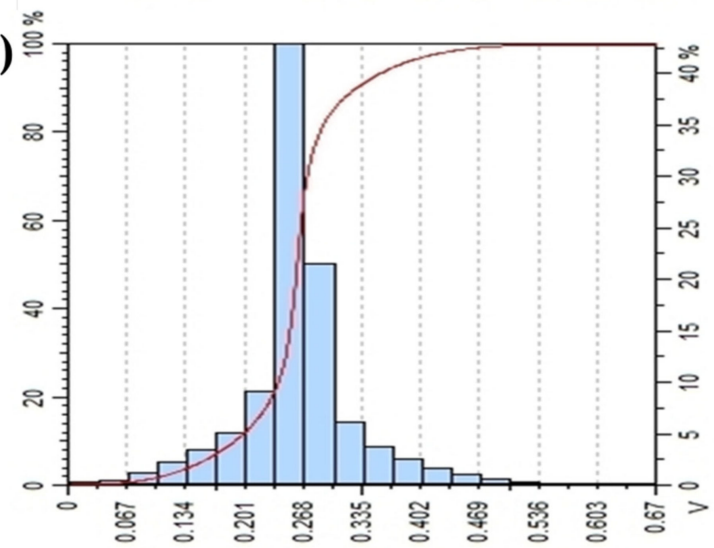

Figure 6. (a,b) Topographical 2D AFM images; (c,d) identical 3D AFM images; (e,f) typical histogram of particle size distribution; $(\mathbf{g}, \mathbf{h})$ typical histogram of particles volume distribution of the synthesized Carbopol/ZnO hybrid nanoparticles gel. 
3.6. Particle Shape and Size Analysis of Synthesized $\mathrm{ZnO} \mathrm{NPs} \mathrm{and} \mathrm{Carbopol/ZnO} \mathrm{Hybrid}$ Nanoparticles Gel

The synthesized ZnO NPs and Carbopol/ZnO hybrid nanoparticles gel were investigated using a high-emission SEM microscope. Moreover, the obtained Carbopol/ZnO hybrid nanoparticles gel was further examined using a TEM microscope. The SEM and TEM results supported the results obtained by the AFM images. From Figure 7a, it could observed that the ZnO NPs were formed in nanospheres with uniform spherical shapes and sizes, as the majority of the particles lie in the nanodomain range. Moreover, the microstructure of nanocrystalline $\mathrm{ZnO}$ NPs has a skeletal form resulting from the aggregation process. These agglomerates have taken the shape of faceted crystals, which is characterized by a high porosity. Hutera et al. and Chai et al. reported similar results [93,94]. Figure 7b illustrates an SEM photograph of synthesized Carbopol/ZnO hybrid nanoparticles gel. It is clear that the Carbopol/ZnO hybrid nanoparticles gel have formed from Carbopol gel well-comprised by $\mathrm{ZnO}$ nanoclusters, and have created a network of ZnO NPs series connected to each other by the Carbopol gel. These observations were confirmed by the HR-TEM micrograph, as shown in Figure 8.
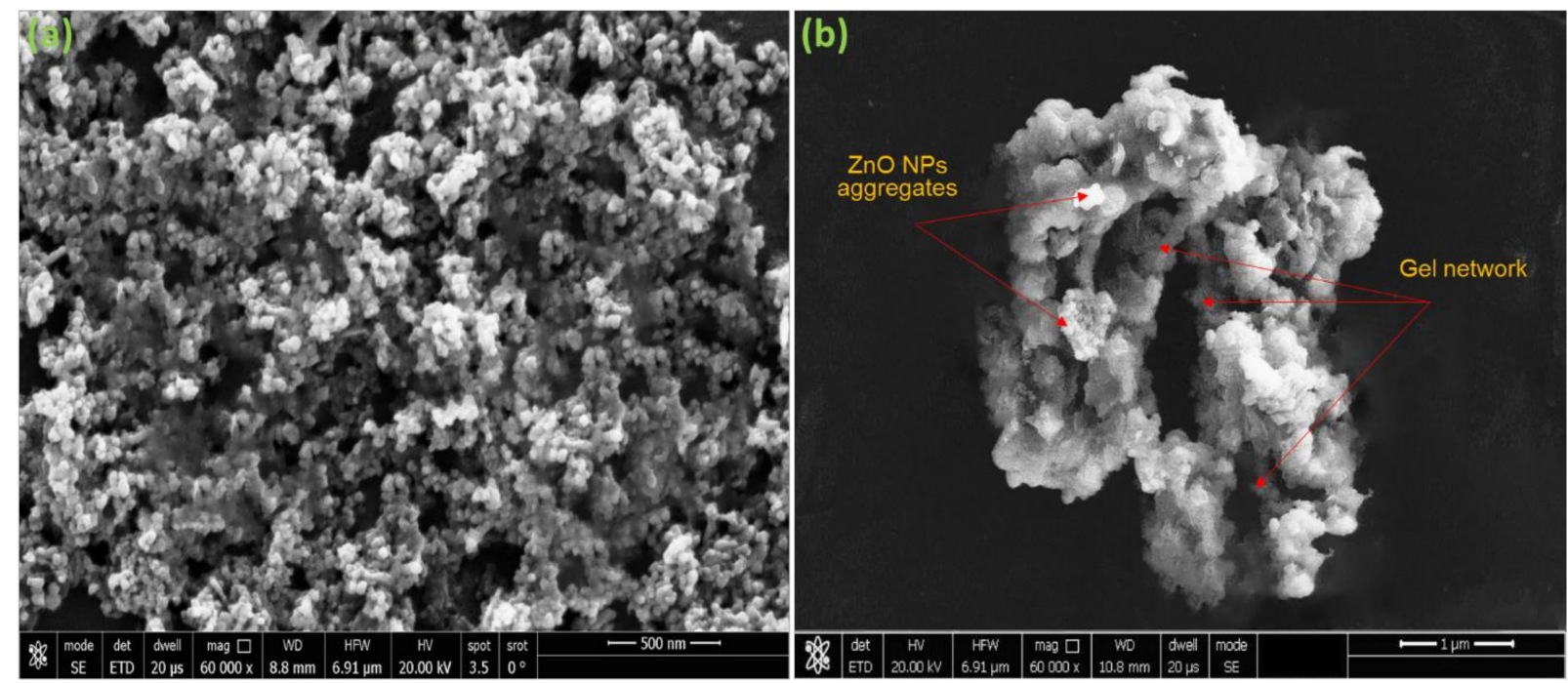

Figure 7. Field-Emission SEM image of (a) ZnO NPs and (b) Carbopol/ZnO hybrid nanoparticles gel.

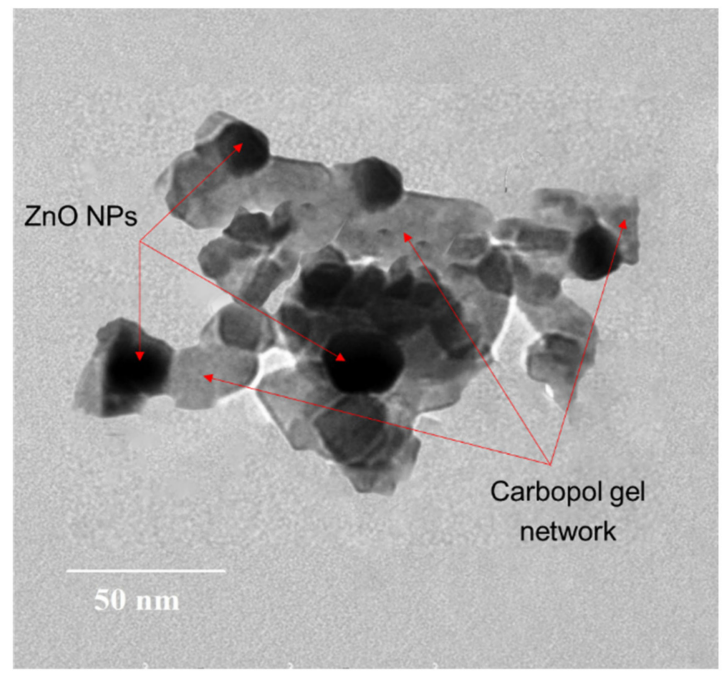

Figure 8. High-Resolution TEM image of the synthesized Carbopol/ZnO hybrid nanoparticles gel. 
As shown in the TEM image, quazi-spherical ZnO NPs with sharp edges dispersed in the gel network. Moreover, the TEM image confirmed that the size of the Carbopol/ZnO hybrid nanoparticles was $\sim 38 \mathrm{~nm}$. Previous studies mention similar TEM morphologies. Mohammed et al. reported that the particle size investigations of the unloaded Carbopol AquaSF-1 nanogel and vancomycin-loaded Carbopol nanogel (VAC-AquaSF1) revealed that the prepared drug-loaded nanogel particles were almost spherical with a smooth morphology, appeared as black dots with bright surroundings, and were well dispersed and separated on the surface. The average particle size was found to be less than $115 \mathrm{~nm}$ and larger than unloaded nanogel, which was about lower than $100 \mathrm{~nm}$ [95]. In addition, Al-Awady et al. concluded that the TEM image of the dried-up suspension of collapsed Carbopol Aqua SF1 nanogel particles contained spherical particles of about $100 \pm 20 \mathrm{~nm}$, which matches with the average particle diameter measured by the Zetasizer analyzer [96].

\subsection{DLS and Zeta-Potential of the Synthesized ZnO NPs and Carbopol/ZnO Hybrid Nanoparticles Gel}

The synthesized ZnO NPs and Carbopol/ZnO hybrid nanoparticles gel were investigated using the dynamic laser scattering (DLS) technique and were subjected to zeta potential measurements. Figure 9 shows that the median particle size value of ZnO NPs was $\sim 60 \mathrm{~nm}$, and $\sim 40 \mathrm{~nm}$ for Carbopol/ZnO hybrid nanoparticles gel, which matched with the particle size estimated by the TEM image analysis. This difference may be attributed to the fact that the Carbopol gel improved the dispersity of the $\mathrm{ZnO}$ NPs and reduced the cluster aggregations.

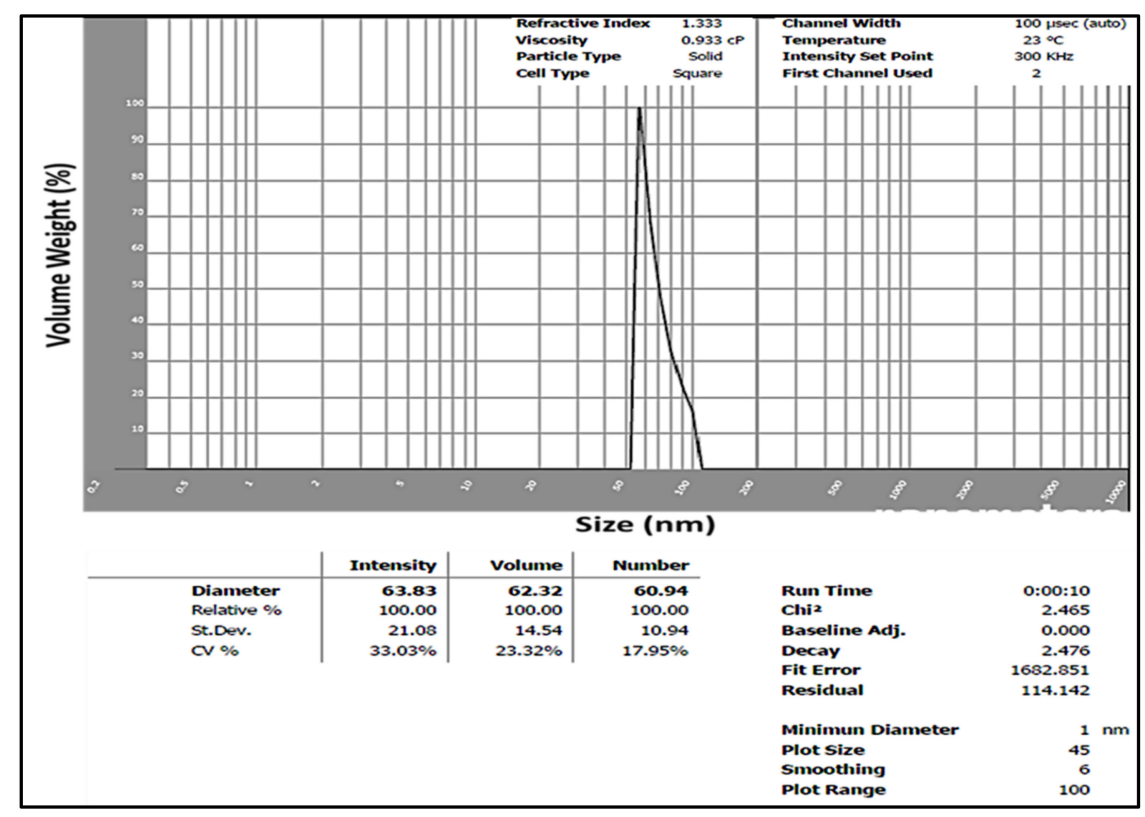

Figure 9. Particle size distribution of ZnO NPs measured by DLS.

Nanocrystals usually undergo agglomeration when dispersed in solutions, and this behavior has a major impact on the reactivity and responsiveness of nanomaterials when exposed to various cells or organisms. Therefore, the hydrodynamic sizes of the $\mathrm{ZnO}$ NPs samples suspended in Carbopol gel were measured at a neutral $\mathrm{pH}$. According to the Derjaguin-Landau-Verwey-Overbeek (DLVO) model, the agglomeration of nonstabilized ZnO NPs nanocrystals depends on the repulsive interaction arising from an electrostatic force and the van der Waals force of attraction. Because the surface charges of nanocrystals influence the electrostatic repulsive force, nanoparticles with a larger zeta potential will generally reduce in hydrodynamic size. Punnoose et al. mentioned similar results [97]. 
The zeta-potential values of the $\mathrm{ZnO}$ NPs and Carbopol/ZnO hybrid nanoparticles gel were found at $5.82 \mathrm{mV}$ (Figure 10), and $-21.7 \mathrm{mV}$, respectively. Consequently, one can conclude from the results that the high value of zeta-potential might be interpreting the acquired high bioactivity of the Carbopol/ZnO hybrid nanoparticles gel against different types of bacterial species. It is clear from the results that the surface of the Carbopol/ZnO hybrid nanoparticles gel is negatively charged at a neutral $\mathrm{pH}$. The high negative zeta potential observed for the Carbopol/ZnO hybrid nanoparticles gel signifies an efficient dispersion of the $\mathrm{ZnO} N$ Ps powder in the neutral $\mathrm{pH}$ gel, where the well-dispersed powder provides a high effective surface for killing the bacteria [98]. The ZnO NPs stabilization by Carbopol gel is expected to modify the net surface charge density and inter-particle interactions. When the $\mathrm{ZnO}$ NPs are dispersed in a Carbopol gel, the nanocrystals undergo surface ionization and the adsorption of ions resulting in the generation of an enhanced surface charge. This surface charge leads to an electric potential between the ZnO NPs nanocrystals and the bulk of the dispersion medium (Carbopol gel), and this is measured as zeta potential in experiments that use electrophoretic/electrokinetic techniques. Besides, Weldrick et al. stated that the alcalase-coated clindamycin-loaded Carbopol Nanogels were narrow, although not monodisperse. The effect of $\mathrm{pH}$ on the nanogels not only causes swelling and de-swelling, but also changes the values of the zeta potential. There is an overall increase in the zeta potential according to the $\mathrm{pH}$ value of the solutions. The surface carboxylic groups of Carbopol gel that partially dissociate cause the appearance of a negative surface charge. Moreover, the nanogel particles are always negatively charged across the whole range of the $\mathrm{pH}$, which allows for the cationic entities of materials [99].

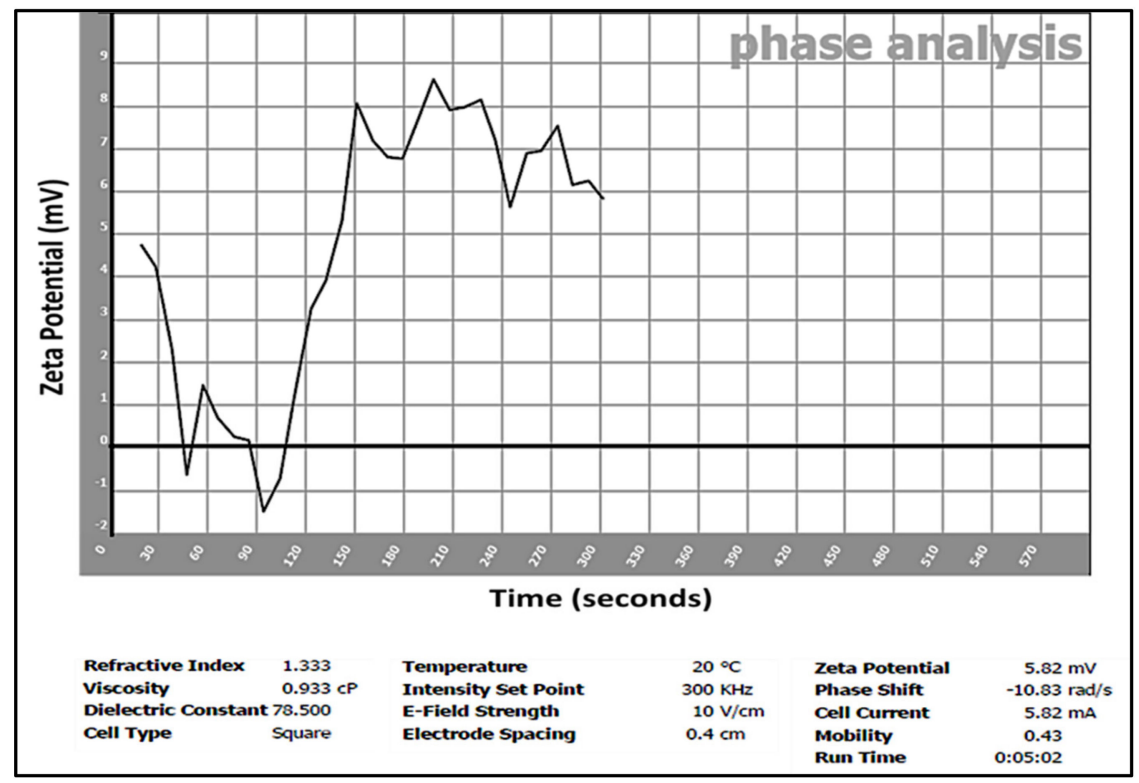

Figure 10. Zeta potential of ZnO NPs measured as a function of time.

A previous study by Mohammed, et al. reported that the particle size distribution and the zeta potential of bare Carbopol nanogel at $\mathrm{pH} 6.5$ equaled $94.66 \mathrm{~nm}$ and $-31.8 \mathrm{mV}$, respectively, while, the particle size distribution and the zeta potential of vancomycinloaded Carbopol nanogel at $\mathrm{pH} 6.5$ reached $391 \mathrm{~nm}$ and $-38.5 \mathrm{mV}$, respectively [95]. Moreover, Al-Awadyet al. reported that the average particle diameter of $0.05 \mathrm{wt} \%$ Carbopol Aqua SF1 was found to be approximately $100 \mathrm{~nm}$, while the zeta potential was $-44 \mathrm{mV}$, which indicates that the Carbopol Aqua SF1 nanogel particles have high stability when suspended in MilliQ water at $\mathrm{pH}$ 5.5. Furthermore, they measured the value of the average particle diameter of berberine-loaded Carbopol Aqua SF1 nanogel and found it to be about $135 \mathrm{~nm}$ at $\mathrm{pH}$ 5.5, while the berberine-loaded Carbopol Aqua SF1 nanogel suspension has a zeta potential value of $-40 \mathrm{mV}$ [96]. 


\subsection{Bioactivity of Carbopol/ZnO Hybrid Nanoparticles Gel}

Gram-positive bacteria (Bacillus subtilis and Staphylococcus aureus) and gram-negative bacteria (K. pneumoniae) are pathogenic bacteria, which is one of the ESKAPE pathogens with a multi-drug resistance. The emergence of resistance in Bacillus subtilis, Staphylococcus aureus, and K. pneumoniae causes high mortality and morbidity. Gram-positive and gramnegative bacteria have developed an ability to accumulate diverse resistance mechanisms. The rise in antibiotic resistance and emergence of antibiotic-resistant superbugs is stressing the need for innovative strategies to develop new antimicrobials [100]. In this study, two types of bacterial organisms, gram-positive bacteria (Bacillus subtilis and Staphylococcus aureus) and gram-negative bacteria (K. pneumoniae), were used to investigate the antibacterial activity of the prepared Carbopol/ZnO hybrid nanoparticles gel. The observed results revealed that the inhibition activity of the Carbopol/ZnO hybrid nanoparticles gel was more active than the reference sample of ampicillin (see Figure 11), where the inhibition zone diameters were found at $27 \pm 0.71$ and $33 \pm 0.62$ for Bacillus subtilis and K. pneumoniae (ATCC 13883), respectively. Thus, the obtained values of the inhibition zone can illustrate the great inhibition effect of Carbopol/ZnO hybrid nanoparticles gel against the different types of bacterial strains. However, the value of the inhibition zone of Carbopol/ZnO hybrid nanoparticles gel against Staphylococcus aureus reached $37 \pm 0.78 \mathrm{~mm}$ with a high sensitivity without any contamination effect $[101,102]$. In the same context, the ampicillin showed an asymmetrical and moderate effect on the inhibition of bacterial growth for both Bacillus subtilis and Staphylococcus aureus, while also facing a drastic resistance from the $K$. pneumonia, and thus it did not record any activity.

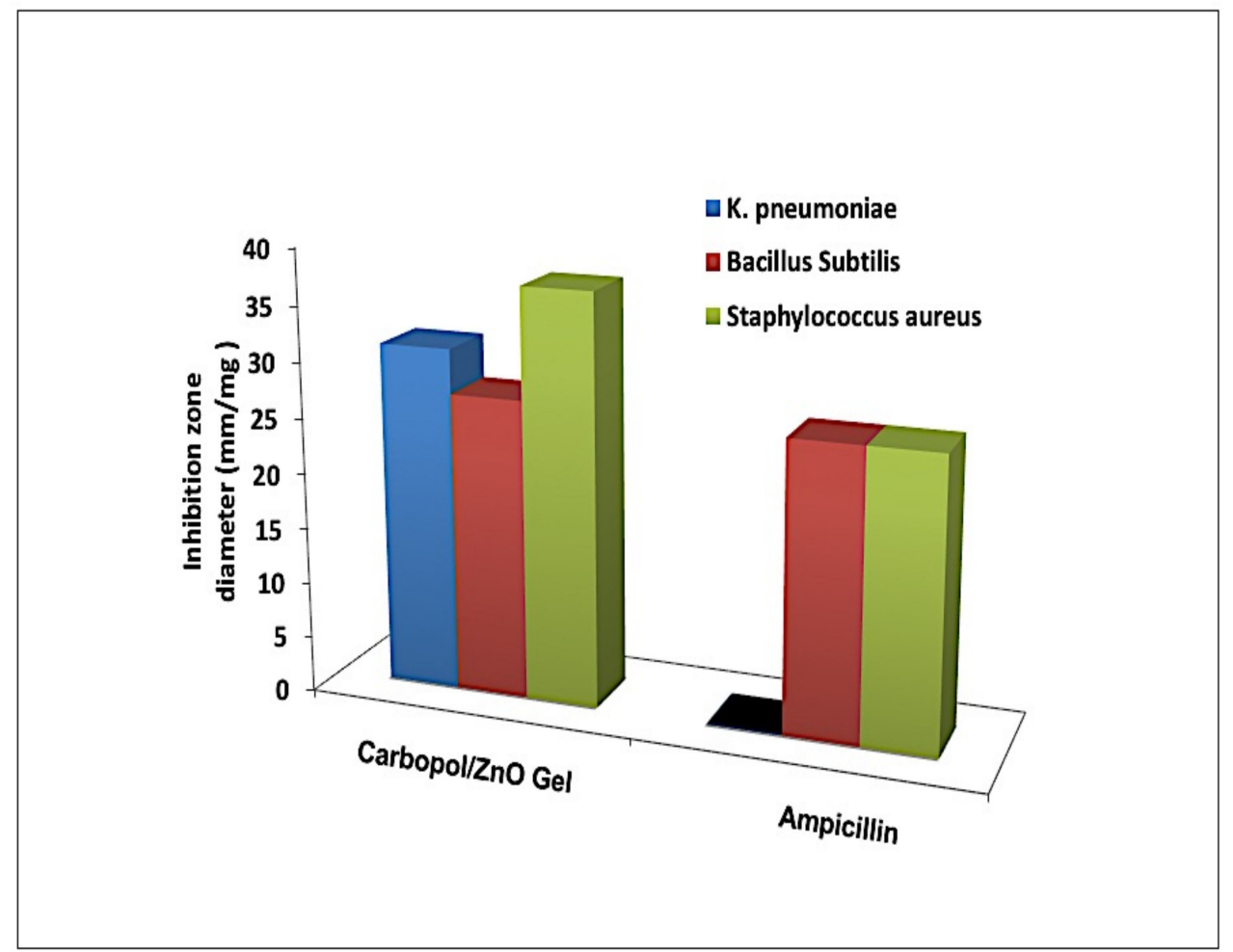

Figure 11. Antibacterial activity of the synthesized Carbopol/ZnO hybrid nanoparticles gel as compared with ampicillin standard samples.

Sadek et al. mentioned that the value of the inhibition zone of bare metal nanoparticles (e.g., nZVI) against Staphylococcus aureus reached $9 \mathrm{~mm}$ [103]. Moreover, many previous studies reported the efficient antibacterial activity of inorganic nanogels-based metals/metals oxides. Whaid et al. have investigated the antibacterial activity of $\beta$ chitin/ZnO nanocomposite hydrogels against $S$. aureus and E. coli, which exhibited good 
bactericidal properties, and mentioned that collagen-dextran-ZnO NPs nanocomposites could serve as a kind of promising wound dressing with sustained drug delivery properties [104].

Gokmen et al. have studied the synergetic effect of hydrogel, nanoTiO ${ }_{2}$ doped hydrogel, and $\mathrm{ZnO}$ nanoflowers deposited nano $\mathrm{TiO}_{2}$ doped in biodegradable hydrogel against Staphylococcus aureus and Escherichia coli. They reported that these composites have achieved antibacterial activity towards these two bacteria as follows: $79.45 \%, 90.37 \%$, and 99.98\% against Staphylococcus aureus; and 57.03\%, 80.79\%, and $97.46 \%$ against Escherichia coli [105]. In addition, Yang et al. have mentioned that due to the high hydrophilicity, unique three-dimensional network, fine biocompatibility, and cell adhesion, the hydrogels are one of the suitable biomaterials for drug delivery in antimicrobial areas. Furthermore, they also stated that the antimicrobial hydrogels loaded with metal nanoparticles are a potential method to solve antibiotic resistance [106]. Additionally, Scalzo et al. studied the interaction effects of polyacrylic acid polymers (Carbopol 940) on the antimicrobial activity of methyl parahydroxybenzoate against some gram-negative and gram-positive bacteria and yeast, and the results revealed that the hydrophilic polymer, widely employed in many formulations, exerts, on the contrary, an interesting synergism on the microbicidal activity of the preserving agent against E. coli and P. Aeruginosa [107].

It is known that gram-negative bacteria are surrounded by a thin peptidoglycan cell wall, which itself is surrounded by an outer membrane containing lipopolysaccharide, while gram-positive bacteria lack an outer membrane but are surrounded by layers of peptidoglycan many times thicker than in gram-negative bacteria. According to the previous studies, several mechanisms have been suggested to specify the antibacterial property of metals/metals oxides and hydrogels, including the penetration of the cell envelope by these metal oxides/hydrogels, and damaging the cell membrane due to the production of reactive oxygen species (ROS). The elevated ROS leads to producing effects on the bacteria, of which lipid peroxidation is one of them, which affects the bacterial membrane's integrity [51]. Furthermore, the elevated amounts of ROS cause oxidative stress within cells, eventually leading to cell death. ROS generation is known to be a prominent mechanism of cell death when cells are treated with nanoparticles [108,109]. It could assign the high antimicrobial activity of Carbopol/ZnO hybrid nanoparticles gel to the high stability of Carbopol/ZnO hybrid nanoparticles gel for a long time, which allows the included $\mathrm{ZnO}$ NPs within Carbopol gel to effectively produce more ROS. The Carbopol/ZnO hybrid nanoparticles gel has a distinctive antibacterial activity towards both the gram-positive and gram-negative bacteria. However, the significant activity of Carbopol/ZnO hybrid nanoparticles gel against Staphylococcus aureus may be attributed to the amont of ROS species that can easily penetrate the cell wall of gram-positive bacteria, due to its lack of an outer membrane resulting in high bacterial inhibition. On the contrary, the ROS species forfeits the ability to penetrate the thick cell wall of gram-negative bacteria, which makes it less effective [110].

\section{Conclusions}

High purity ZnO NPs, as well as Carbopol/ZnO hybrid nanoparticles gel, were synthesized using a wet chemical precipitation reaction with a high yield under the effect of the ultrasonic wave irradiation. The properties of the produced nanoparticles and the hybrid system were characterized using different characterization techniques. The obtained results revealed that the synthesized nanoparticles were composed mainly of $\mathrm{ZnO}$ wurtzite crystalline phases with a quazi-spherical shape and median particle sizes of $59.9 \mathrm{~nm}$, a particle size distribution between $\sim 9$ and $\sim 93 \mathrm{~nm}$, and a surface area of $54.26 \mathrm{~m}^{2} / \mathrm{g}$. It could be stated that the high values of zeta-potential in the Carbopol/ZnO hybrid nanoparticles $(-21.7 \mathrm{mV})$ might be interpreted as the reason for the high bioactivity of Carbopol stabilized ZnO NPs against different bacterial species. The antibacterial activity of Carbopol/ZnO hybrid nanoparticles gel was screened against different gram-positive and gram-negative bacterial strains. It was found that the inhibition activity of Carbopol/ZnO 
hybrid nanoparticles gel was higher than the reference sample of the ampicillin drug itself. This study has highlighted the properties of Carbopol/ZnO hybrid nanoparticles gel as a potent antibacterial hybrid system with regards to the growth inhibition of microorganisms. This makes Carbopol/ZnO hybrid nanoparticles gel an interest of note as an efficient bacterial inhibitor for many applications.

Author Contributions: Conceptualization S.H.I.; A.H.; T.A.I.; H.H.M.; W.H.M.; W.M.D.; Methodology, A.H.; W.M.D.; formal analysis, S.H.I.; A.H.; W.H.M.; investigation, T.A.I.; H.H.M.; resources, S.H.I.; A.H.; H.H.M.; writing—original draft preparation, A.H.; writing—review and editing, W.H.M.; W.M.D.; All authors have read and agreed to the published version of the manuscript.

Funding: This research was funded by the Taif University Researchers Supporting Project number (TURSP-2020/134), Taif University, Taif, Saudi Arabia.

Institutional Review Board Statement: Not applicable.

Informed Consent Statement: Not applicable.

Data Availability Statement: All data are available in this manuscript.

Acknowledgments: The authors are grateful to Taif University Researchers Supporting Project number (TURSP-2020/134), Taif University, Taif, Saudi Arabia for their financial support. We gratefully acknowledge the faculty of nanotechnology for postgraduate studies, Cairo University (https: / fnt.cu.edu.eg/en/) (accessed on 1 July 2021) for providing facilities.

Conflicts of Interest: The authors declare no conflict of interest.

\section{References}

1. Jiang, J.; Pi, J.; Cai, J. The advancing of zinc oxide nanoparticles for biomedical applications. Available online: https://www. hindawi.com/journals/bca/2018/1062562/ (accessed on 7 July 2021).

2. Rasmussen, J.W.; Martinez, E.; Louka, P.; Wingett, D.G. Zinc oxide nanoparticles for selective destruction of tumor cells and potential for drug delivery applications. Exp. Opin. Drug Deliv. 2010, 7, 1063-1077. [CrossRef]

3. Hamdy, A.; Ismail, S.H.; Ebnalwaled, A.A.; Mohamed, G.G. Characterization of Superparamagnetic/Monodisperse PEG-Coated Magnetite Nanoparticles Sonochemically Prepared from the Hematite Ore for Cd(II) Removal from Aqueous Solutions. J. Inorg. Organomet. Polym. Mater. 2021, 31, 397-414. [CrossRef]

4. Chieng, B.W.; Loo, Y.Y. Synthesis of ZnO nanoparticles by modified polyol method. Mater. Lett. 2012, 73, 78-82. [CrossRef]

5. Banerjee, P.; Chakrabarti, S.; Maitra, S.; Dutta, B.K. Zinc oxide nano-particles-sonochemical synthesis, characterization and application for photo-remediation of heavy metal. Ultrason. Sonochem. 2012, 19, 85-93. [CrossRef] [PubMed]

6. Ghoshal, T.; Biswas, S.; Paul, M.; De, S.K. Synthesis of $\mathrm{ZnO}$ nanoparticles by solvothermal method and their ammonia sensing properties. J. Nanosci. Nanotechnol. 2009, 9, 5973-5980. [CrossRef] [PubMed]

7. Bharti, D.B.; Bharati, A. Synthesis of ZnO nanoparticles using a hydrothermal method and a study its optical activity. Luminescence 2017, 32, 317-320. [CrossRef]

8. Pineda-Reyes, A.M.; Olvera, M.d.l.L. Synthesis of ZnO nanoparticles from water-in-oil (w/o) microemulsions. Mater. Chem. Phys. 2018, 203, 141-147. [CrossRef]

9. Somoghi, R.; Purcar, V.; Alexandrescu, E.; Gifu, I.C.; Ninciuleanu, C.M.; Cotrut, C.M.; Oancea, F.; Stroescu, H. Synthesis of Zinc Oxide Nanomaterials via Sol-Gel Process with Anti-Corrosive Effect for Cu, Al and Zn Metallic Substrates. Coatings 2021, 11, 444. [CrossRef]

10. Adam, R.E.; Pozina, G.; Willander, M.; Nur, O. Synthesis of ZnO nanoparticles by co-precipitation method for solar driven photodegradation of Congo red dye at different pH. Photonics Nanostructures Fundam. Appl. 2018, 32, 11-18. [CrossRef]

11. Lijuan, A.N.; Jun, W.; Tiefeng, Z.; Hanlin, Y.; Zhihui, S. Synthesis of ZnO nanoparticles by direct precipitation method. Adv. Mat. Res. 2012, 380, 335-338.

12. Naveed Ul Haq, A.; Nadhman, A.; Ullah, I.; Mustafa, G.; Yasinzai, M.; Khan, I. Synthesis approaches of zinc oxide nanoparticles: The dilemma of ecotoxicity. J. Nanomater. 2017, 2017. [CrossRef]

13. Zhang, Y.; Ram, M.K.; Stefanakos, E.K.; Goswami, D.Y. Synthesis, characterization, and applications of ZnO nanowires. J. Nanomater. 2012, 2012, 1-22. [CrossRef]

14. Chaudhary, S.; Umar, A.; Bhasin, K.K.; Baskoutas, S. Chemical sensing applications of ZnO nanomaterials. Materials 2018, 11, 287. [CrossRef] [PubMed]

15. Chen, R.; Huo, L.; Shi, X.; Bai, R.; Zhang, Z.; Zhao, Y.; Chang, Y.; Chen, C. Endoplasmic reticulum stress induced by zinc oxide nanoparticles is an earlier biomarker for nanotoxicological evaluation. ACS Nano 2014, 8, 2562-2574. [CrossRef]

16. Food and Drug Administration. Select Committee on GRAS Substances (SCOGS) Opinion: Zinc Salts 2015. Washington, DC. 2015. Available online: https://www.accessdata.fda.gov/scripts/cdrh/cfdocs/cfffr/CFRSearch.cfm (accessed on 1 April 2020). 
17. Mirzaei, H.; Darroudi, M. Zinc oxide nanoparticles: Biological synthesis and biomedical applications. Ceram. Int. 2017, 43, 907-914. [CrossRef]

18. Siddiqi, K.S.; Rahman, A.; Husen, A. Properties of zinc oxide nanoparticles and their activity against microbes. Nanoscale Res. Lett. 2018, 13, 1-13. [CrossRef]

19. Smijs, T.G.; Pavel, S. Titanium dioxide and zinc oxide nanoparticles in sunscreens: Focus on their safety and effectiveness. Nanotechnol. Sci. Appl. 2011, 4, 95. [CrossRef]

20. Sahoo, S.; Maiti, M.; Ganguly, A.; George, J.J.; Bhowmick, A.K. Effect of zinc oxide nanoparticles as cure activator on the properties of natural rubber and nitrile rubber. J. Appl. Polym. Sci. 2007, 105, 2407-2415. [CrossRef]

21. Hatamie, A.; Khan, A.; Golabi, M.; Turner, A.P.F.; Beni, V.; Mak, W.C.; Sadollahkhani, A.; Alnoor, H.; Zargar, B.; Bano, S.; et al. Zinc oxide nanostructure-modified textile and its application to biosensing, photocatalysis, and as antibacterial material. Langmuir 2015, 31, 10913-10921. [CrossRef]

22. Sricharussin, W.; Threepopnatkul, P.; Neamjan, N. Effect of various shapes of zinc oxide nanoparticles on cotton fabric for UV-blocking and anti-bacterial properties. Fibers Polym. 2011, 12, 1037-1041. [CrossRef]

23. Kołodziejczak-Radzimska, A.; Jesionowski, T. Zinc oxide—from synthesis to application: A review. Materials 2014, 7, $2833-2881$. [CrossRef]

24. Bica, B.O.; de Melo, J.V.S. Concrete blocks nano-modified with zinc oxide (ZnO) for photocatalytic paving: Performance comparison with titanium dioxide $\left(\mathrm{TiO}_{2}\right)$. Constr. Build. Mater. 2020, 252, 119120. [CrossRef]

25. Ahmed, E.M. Hydrogel: Preparation, characterization, and applications: A review. J. Adv. Res. 2015, 6, 105-121. [CrossRef]

26. Singh, S.K.; Dhyani, A.; Juyal, D. Hydrogel: Preparation, characterization and applications. Pharma Innov. $2017,6,25$.

27. Chai, Q.; Jiao, Y.; Yu, X. Hydrogels for biomedical applications: Their characteristics and the mechanisms behind them. Gels 2017, 3, 6. [CrossRef] [PubMed]

28. Chaterji, S.; Kwon, I.K.; Park, K. Smart polymeric gels: Redefining the limits of biomedical devices. Prog. Polym. Sci. 2007, 32, 1083-1122. [CrossRef]

29. Sultana, F.; Manirujjaman; Imran-Ul-Haque, M.; Arafat, M.; Sharmin, S. An overview of nanogel drug delivery system. J. Appl. Pharm. Sci. 2013, 3, 95-105.

30. Oh, J.K.; Drumright, R.; Siegwart, D.J.; Matyjaszewski, K. The development of microgels/nanogels for drug delivery applications. Prog. Polym. Sci. 2008, 33, 448-477. [CrossRef]

31. Soni, K.S.; Desale, S.S.; Bronich, T.K. Nanogels: An overview of properties, biomedical applications and obstacles to clinical translation. J. Controll. Release 2016, 240, 109-126. [CrossRef]

32. Kabanov, A.V.; Vinogradov, S.V. Nanogels as pharmaceutical carriers: Finite networks of infinite capabilities. Angew. Chem. Int. Ed. 2009, 48, 5418-5429. [CrossRef]

33. Yin, Y.; Hu, B.; Yuan, X.; Cai, L.; Gao, H.; Yang, Q. Nanogel: A versatile nano-delivery system for biomedical applications. Pharmaceutics 2020, 12, 290. [CrossRef] [PubMed]

34. Patra, J.K.; Das, G.; Fraceto, L.F.; Campos, E.V.R.; Rodriguez-Torres, M.P.; Acosta-Torres, L.S.; Diaz-Torres, L.A.; Grillo, R.; Swamy, M.K.; Sharma, S.; et al. Nano based drug delivery systems: Recent developments and future prospects. J. Nanobiotechnol. 2018, 16, 1-33. [CrossRef] [PubMed]

35. Mohanambal, E. Formulation and Evaluation of $\mathrm{pH}$ Triggered in Situ Gelling System of Levofloxacin. M.Sc. Thesis, Madurai Medical College, Madurai, India, 2010.

36. Gutowski, I.A. The Effects of $\mathrm{pH}$ and Concentration on the Rheology of Carbopol Gels. M.Sc. Thesis, Department of Physics: Simon Fraser University, Burnaby, BC, Canada, 2010.

37. Alam, S.; Algahtani, M.S.; Ahmad, M.Z.; Ahmad, J. Investigation utilizing the HLB concept for the development of moisturizing cream and lotion: In-vitro characterization and stability evaluation. Cosmetics 2020, 7, 43. [CrossRef]

38. Lorca, S.; Santos, F.; Fernández Romero, A.J. A Review of the Use of GPEs in Zinc-Based Batteries. A Step Closer to Wearable Electronic Gadgets and Smart Textiles. Polymers 2020, 12, 2812. [CrossRef] [PubMed]

39. Sirelkhatim, A.; Mahmud, S.; Seeni, A.; Kaus, N.H.M.; Ann, L.C.; Bakhori, S.K.M.; Hasan, H.; Mohamad, D. Review on zinc oxide nanoparticles: Antibacterial activity and toxicity mechanism. Nano-Micro Lett. 2015, 7, 219-242. [CrossRef]

40. Wang, L.; Hu, C.; Shao, L. The antimicrobial activity of nanoparticles: Present situation and prospects for the future. Int. J. Nanomed. 2017, 12, 1227. [CrossRef]

41. Malmsten, M. Antimicrobial and antiviral hydrogels. Soft Matter. 2011, 7, 8725-8736. [CrossRef]

42. Shah, B.; Davidson, P.M.; Zhong, Q. Nanodispersed eugenol has improved antimicrobial activity against Escherichia coli O157: H7 and Listeria monocytogenes in bovine milk. Int. J. Food Microbiol. 2013, 161, 53-59. [CrossRef] [PubMed]

43. Kupnik, K.; Primožič, M.; Kokol, V.; Leitgeb, M. Nanocellulose in Drug Delivery and Antimicrobially Active Materials. Polymers 2020, 12, 2825. [CrossRef] [PubMed]

44. Da Silva, B.L.; Abuçafy, M.P.; Manaia, E.B.; Junior, J.A.O.; Chiari-Andréo, B.G.; Pietro, R.C.R.; Chiavacci, L.A. Relationship between structure and antimicrobial activity of zinc oxide nanoparticles: An overview. Int. J. Nanomed. 2019, 14, 9395. [CrossRef]

45. Diez-Pascual, A.M. Antibacterial nanocomposites based on thermosetting polymers derived from vegetable oils and metal oxide nanoparticles. Polymers 2019, 11, 1790. [CrossRef] [PubMed]

46. Nazoori, E.S.; Kariminik, A. In vitro evaluation of antibacterial properties of zinc oxide nanoparticles on pathogenic prokaryotes. J. Appl. Biotechnol. Rep. 2018, 5, 162-165. [CrossRef] 
47. Alamdari, S.; Ghamsari, M.S.; Lee, C.; Han, W.; Park, H.; Tafreshi, M.J.; Afarideh, H.; Ara, M.H.M. Preparation and characterization of zinc oxide nanoparticles using leaf extract of sambucus ebulus. Appl. Sci. 2020, 10, 3620. [CrossRef]

48. Slavin, Y.N.; Asnis, J.; Häfeli, U.O.; Bach, H. Metal nanoparticles: Understanding the mechanisms behind antibacterial activity. J. Nanobiotechnol. 2017, 15, 1-20. [CrossRef] [PubMed]

49. Agarwal, H.; Menon, S.; Kumar, S.V.; Rajeshkumar, S. Mechanistic study on antibacterial action of zinc oxide nanoparticles synthesized using green route. Chem. Biol. Interact. 2018, 286, 60-70. [CrossRef] [PubMed]

50. Tiwari, V.; Mishra, N.; Gadani, K.; Solanki, P.S.; Shah, N.A.; Tiwari, M. Mechanism of anti-bacterial activity of zinc oxide nanoparticle against carbapenem-resistant Acinetobacter baumannii. Front. Microbiol. 2018, 9, 1218. [CrossRef]

51. Jana, S.; Manna, S.; Nayak, A.K.; Sen, K.K.; Basu, S.K. Carbopol gel containing chitosan-egg albumin nanoparticles for transdermal aceclofenac delivery. Colloids Surf. B Biointerfaces 2014, 114, 36-44. [CrossRef]

52. Sareen, R.; Kumar, S.; Gupta, G.D. Meloxicam carbopol-based gels: Characterization and evaluation. Curr. Drug Deliv. 2011, 8, 407-415. [CrossRef]

53. Bonacucina, G.; Cespi, M.; Misici-Falzi, M.; Palmieri, G.F. Rheological evaluation of silicon/carbopol hydrophilic gel systems as a vehicle for delivery of water insoluble drugs. AAPS J. 2008, 10, 84-91. [CrossRef]

54. Purwaningsih, S.Y.; Pratapa, S.; Triwikantoro; Darminto. Nano-sized ZnO powders prepared by co-precipitation method with various $\mathrm{pH}$. In Proceedings of the 3rd International Conference on Advanced Materials Science and Technology (ICAMST 2015), Proceedings of the AIP Conference 1725, 020063 (2016); Semarang, Indonesia, 6-7th October 2015, AIP Publishing LLC: Melville, NY, USA, 2016. [CrossRef]

55. Blanco-Fuente, H.; Esteban-Fernández, B.; Blanco-Méndez, J.; Otero-Espinar, F. Use of $\beta$-cyclodextrins to prevent modifications of the properties of carbopol hydrogels due to carbopol-drug interactions. Chem. Pharm. Bull. 2002, 50, 40-46. [CrossRef]

56. Suhail, M.; Wu, P.-C.; Minhas, M.U. Using carbomer-based hydrogels for control the release rate of diclofenac sodium: Preparation and in vitro evaluation. Pharmaceuticals 2020, 13, 399. [CrossRef]

57. Lamberti, G.; Caccavo, D.; Cascone, D.I.S. Mathematical Description of Hydrogels' Behavior for Biomedical Applications; Universita Degli Studi Di Salerno: Fisciano, Italy, 2013.

58. Viyoch, J.; Klinthong, N.; Siripaisal, W. Development of oil-in-water emulsion containing Tamarind fruit pulp extract I. Physical characteristics and stability of emulsion. Naresuan Univer. J. Sci. Technol. NUJST 2013, 11, $29-44$.

59. Ethier, A.; Bansal, P.; Baxter, J.; Langley, N.; Richardson, N.; Patel, A.M. The role of excipients in the microstructure of Topical semisolid drug products. In The Role of Microstructure in Topical Drug Product Development; Springer: Amsterdam, The Netherlands, 2019; pp. 155-193.

60. Da Silva Ávila, D.M.; Zanatta, R.F.; Scaramucci, T.; Aoki, I.V.; Torres, C.R.G.; Borges, A.B. Randomized in situ trial on the efficacy of Carbopol in enhancing fluoride/stannous anti-erosive properties. J. Dent. 2020, 101, 103347. [CrossRef]

61. Abdullah, G.Z.; Abdulkarim, M.F.; Mallikarjun, C.; Mahdi, E.S.; Basri, M.; Abdul Sattar, M.; Noor, A.M. Carbopol 934, 940 and Ultrez 10 as viscosity modifiers of palm olein esters based nano-scaled emulsion containing ibuprofen. Pak. J. Pharm. Sci. 2013, 26, 75-83.

62. Fevola, M.J.; Walters, R.M.; LiBrizzi, J.J. A new approach to formulating mild cleansers: Hydrophobically-modified polymers for irritation mitigation. In Polymeric Delivery of Therapeutics; ACS Publications: Washington, DC, USA, 2010; pp. 221-242.

63. Varges, R.P.; Costa, C.M.; Fonseca, B.S.; Naccache, M.F.; Mendes, P.R.D. Rheological characterization of Carbopol ${ }^{\circledR}$ dispersions in water and in water/glycerol solutions. Fluids 2019, 4, 3. [CrossRef]

64. Panzade, P.; Puranik, P.K. Carbopol polymers: A versatile polymer for pharmaceutical applications. Res. J. Pharm. Technol. 2010, 3, 672-675.

65. Hamdy, A. Experimental Study of the Relationship Between Dissolved Iron, Turbidity, and Removal of Cu(II) Ion from Aqueous Solutions Using Zero-Valent Iron Nanoparticles. Arab. J. Sci. Eng. 2020, 46, 1-23. [CrossRef]

66. Suntako, R. Effect of zinc oxide nano-gel synthesized by a precipitation method on mechanical and morphological properties of the CR foam. Bull. Mater. Sci. 2015, 38, 1033-1038. [CrossRef]

67. Chikkanna, M.M.; Neelagund, S.E.; Rajashekarappa, K.K. Green synthesis of zinc oxide nanoparticles (ZnO NPs) and their biological activity. SN Appl. Sci. 2019, 1, 1-10. [CrossRef]

68. Mashrai, A.; Khanam, H.; Aljawfi, R.N. Biological synthesis of ZnO nanoparticles using C. albicans and studying their catalytic performance in the synthesis of steroidal pyrazolines. Arab. J. Chem. 2017, 10, S1530-S1536.

69. Muhammad, W.; Ullah, N.; Haroon, M.; Abbasi, B.H. Optical, morphological and biological analysis of zinc oxide nanoparticles (ZnO NPs) using Papaver somniferum L. RSC Adv. 2019, 9, 29541-29548. [CrossRef]

70. Zak, A.K.; Razali, R.; Abd Majid, W.H.; Darroudi, M. Synthesis and characterization of a narrow size distribution of zinc oxide nanoparticles. Int. J. Nanomed. 2011, 6, 1399.

71. Baruwati, B.; Kumar, D.K.; Manorama, S.V. Hydrothermal synthesis of highly crystalline ZnO nanoparticles: A competitive sensor for LPG and EtOH. Sens. Actuators B Chem. 2006, 119, 676-682. [CrossRef]

72. Acosta-Humánez, M.; Montes-Vides, L.; Almanza-Montero, O. Sol-gel synthesis of zinc oxide nanoparticle at three different temperatures and its characterization via XRD, IR and EPR. Dyna 2016, 83, 224-228. [CrossRef]

73. Diallo, A.; Ngom, B.D.; Park, E.; Maaza, M. Green synthesis of ZnO nanoparticles by Aspalathus linearis: Structural \& optical properties. J. All. Comp. 2015, 646, 425-430. 
74. Muchuweni, E.; Sathiaraj, T.; Nyakotyo, H. Hydrothermal synthesis of ZnO nanowires on rf sputtered Ga and Al co-doped ZnO thin films for solar cell application. J. Alloy Comp. 2017, 721, 45-54. [CrossRef]

75. Taziwa, R.; Meyer, E.; Katwire, D.; Ntozakhe, L. Influence of carbon modification on the morphological, structural, and optical properties of zinc oxide nanoparticles synthesized by pneumatic spray pyrolysis technique. J. Nanomater. 2017, 2017. [CrossRef]

76. Jayachandraiah, C.; Krishnaiah, G. Erbium induced raman studies and dielectric properties of Er-doped ZnO nanoparticles. Adv. Mater. Lett. 2015, 6, 743-748. [CrossRef]

77. Thommes, M.; Kaneko, K.; Neimark, A.V.; Olivier, J.P.; Rodriguez-Reinoso, F.; Rouquerol, J.; Sing, K.S. Physisorption of gases, with special reference to the evaluation of surface area and pore size distribution (IUPAC Technical Report). Pure Appl. Chem. 2015, 87, 1051-1069. [CrossRef]

78. Kołodziejczak-Radzimska, A.; Markiewicz, E.; Jesionowski, T. Structural characterisation of ZnO particles obtained by the emulsion precipitation method. J. Nanomater. 2012, 2012, 15. [CrossRef]

79. Umukoro, E.H.; Peleyejua, M.G.; Idrisa, A.O.; Ngilaab, J.C.; Mabubaab, N.; Rhymanac, L.; Ramasami, P.; Arotiba, O.A. Photoelectrocatalytic application of palladium decorated zinc oxide-expanded graphite electrode for the removal of 4-nitrophenol: Experimental and computational studies. RSC Adv. 2018, 8, 10255-10266. [CrossRef]

80. Ismail, M.A.; Taha, K.K.; Modwi, A.; Khezami, L. ZnO nanoparticles: Surface and X-ray profile analysis. J. Ovonic Res. 2018, 14, 381-393.

81. Thirumavalavan, M.; Huang, K.-L.; Lee, J.-F. Preparation and morphology studies of nano zinc oxide obtained using native and modified chitosans. Materials 2013, 6, 4198-4212. [CrossRef] [PubMed]

82. Nagaraju, P.; Puttaiah, S.H.; Wantala, K.; Shahmoradi, B. Preparation of modified ZnO nanoparticles for photocatalytic degradation of chlorobenzene. Appl. Water Sci. 2020, 10, 1-15. [CrossRef]

83. Ramimoghadam, D.; Hussein, M.Z.B.; Taufiq-Yap, Y.H. Synthesis and characterization of ZnO nanostructures using palm olein as biotemplate. Chem. Central J. 2013, 7, 1-10. [CrossRef]

84. Mustapha, S.; Tijani, J.O.; Ndamitso, M.M.; Abdulkareem, S.A.; Shuaib, D.T.; Mohammed, A.K.; Sumaila, A. The role of kaolin and kaolin/ZnO nanoadsorbents in adsorption studies for tannery wastewater treatment. Sci. Rep. 2020, 10, 1-22. [CrossRef]

85. Mittal, H.; Morajkar, P.P.; Al Alili, A.; Alhassan, S.M. In-situ synthesis of ZnO nanoparticles using gum arabic based hydrogels as a self-template for effective malachite green dye adsorption. J. Polym. Environ. 2020, 28, 1637-1653. [CrossRef]

86. Qin, C.; Li, S.; Jiang, G.; Cao, J.; Guo, Y.; Li, J.; Zhang, B.; Han, S. Preparation of flower-like ZnO nanoparticles in a cellulose hydrogel microreactor. BioResources 2017, 12, 3182-3191. [CrossRef]

87. Omar, L.; Perret, N.; Daniele, S. Self-Assembled Hybrid ZnO nanostructures as supports for copper-based catalysts in the hydrogenolysis of glycerol. Catalysts 2021, 11, 516. [CrossRef]

88. Abou Oualid, H.; Amadine, O.; Essamlali, Y.; Dânounb, K.; Zahouily, M. Supercritical $\mathrm{CO}_{2}$ drying of alginate/zinc hydrogels: A green and facile route to prepare $\mathrm{ZnO}$ foam structures and $\mathrm{ZnO}$ nanoparticles. RSC Adv. 2018, 8, 20737-20747. [CrossRef]

89. Safavinia, L.; Akhgar, M.R.; Tahamipour, B.; Ahmadi, S.A. Green Synthesis of highly dispersed zinc oxide nanoparticles supported on silica gel matrix by daphne oleoides extract and their antibacterial activity. Iran. J. Biotechnol. 2021, 19, 86-95.

90. Hasanpour, M.; Motahari, S.; Jing, D.; Hatami, M. Investigation of the different morphologies of zinc oxide (ZnO) in Cellulose/ZnO hybrid aerogel on the photocatalytic degradation efficiency of methyl orange. Topics Catal. 2021, 2021, 1-14.

91. Wang, Q.; Ji, P.; Yao, Y.; Liu, Y.; Zhang, Y.; Wang, X.; Wang, Y.; Wu, J. Gliadin-mediated green preparation of hybrid zinc oxide nanospheres with antibacterial activity and low toxicity. Sci. Rep. 2021, 11, 1-11.

92. Jassim, A.N.; Alwan, R.M.; Kadhim, Q.A.; Nsaif, A.A. Preparation and characterization of ZnO/polystyrene nanocomposite films using ultrasound irradiation. Nanosci. Nanotechnol. 2016, 6, 17-23.

93. Hutera, B.; Kmita, A.; Olejnik, E.; Tokarski, T. Synthesis of $\mathrm{ZnO}$ nanoparticles by thermal decomposition of basic zinc carbonate. Arch. Metall. Mater. 2013, 58, 489-491. [CrossRef]

94. Chai, M.H.H.; Amir, N.; Yahya, N.; Saaid, I.M. Characterization and colloidal stability of surface modified zinc oxide nanoparticle. J. Phys. Conf. Ser. 2018, 1123, 012007. [CrossRef]

95. Mohammed, W.H.; Ali, W.K.; Al-Awady, M.J. Evaluation of in vitro drug release kinetics and antibacterial activity of vancomycin HCl-loaded nanogel for topical application. J. Pharm. Sci. Res. 2018, 10, 2747-2756.

96. Al-Awady, M.J.; Fauchet, A.; Greenway, G.M.; Paunov, V.N. Enhanced antimicrobial effect of berberine in nanogel carriers with cationic surface functionality. J. Mater. Chem. B 2017, 5, 7885-7897. [CrossRef]

97. Punnoose, A.; Dodge, K.; Rasmussen, J.W.; Chess, J.; Wingett, D.; Anders, C. Cytotoxicity of ZnO nanoparticles can be tailored by modifying their surface structure: A green chemistry approach for safer nanomaterials. ACS Sustain. Chem. Eng. 2014, 2, 1666-1673. [CrossRef]

98. Sapkota, B.B.; Mishra, S.R. Preparation and Photocatalytic Activity Study of p-CuO/n-ZnO composites. MRS Proceedings 2012, 1443, 19-26. [CrossRef]

99. Weldrick, P.J.; San, S.; Paunov, V.N. Advanced Alcalase-Coated Clindamycin-Loaded Carbopol Nanogels for Removal of Persistent Bacterial Biofilms. ACS Appl. Nano Mater. 2021, 4, 1187-1201. [CrossRef]

100. Weldrick, P.J.; Iveson, S.; Hardman, M.J.; Paunov, V.N. Breathing new life into old antibiotics: Overcoming antibacterial resistance by antibiotic-loaded nanogel carriers with cationic surface functionality. Nanoscale 2019, 11, 10472-10485. [CrossRef] 
101. Batool, M.; Khurshid, S.; Daoush, W.M.; Siddique, S.A.; Nadeem, T. Green synthesis and biomedical applications of ZnO nanoparticles: Role of PEGylated-ZnO nanoparticles as doxorubicin drug carrier against MDA-MB-231(TNBC) cells line. Crystals 2021, 11, 344. [CrossRef]

102. Batool, M.; Khurshid, S.; Qureshi, Z.; Daoush, W.M. Adsorption, antimicrobial and wound healing activities of biosynthesised zinc oxide nanoparticles. Chem. Pap. 2021, 75, 893-907. [CrossRef]

103. Sadek, A.H.; Asker, M.S.; Abdelhamid, S.A. Bacteriostatic impact of nanoscale zero-valent iron against pathogenic bacteria in the municipal wastewater. Biologia 2021, 76, 1-25. [CrossRef] [PubMed]

104. Wahid, F.; Zhong, C.; Wang, H.; Hu, X.; Chu, L. Recent advances in antimicrobial hydrogels containing metal ions and metals/metal oxide nanoparticles. Polymers 2017, 9, 636. [CrossRef]

105. Gokmen, F.O.; Temel, S.; Yaman, E. Enhanced antibacterial property by the synergetic effect of $\mathrm{TiO}_{2}$ and $\mathrm{ZnO}$ nano-particles in biodegradable hydrogel. Eur. Sci. J. 2019, 15, 33. [CrossRef]

106. Yang, K.; Han, Q.; Chen, B.; Zheng, Y.; Zhang, K.; Li, Q.; Wang, J. Antimicrobial hydrogels: Promising materials for medical application. Int. J. Nanomed. 2018, 13, 2217. [CrossRef]

107. Scalzo, M.; Orlandi, C.; Simonetti, N.; Cerreto, F. Study of interaction effects of polyacrylic acid polymers (Carbopol 940) on antimicrobial activity of methyl parahydroxybenzoate against some gram-negative, gram-positive bacteria and yeast. J. Pharm. Pharmacol. 1996, 48, 1201-1205. [CrossRef]

108. Alpaslan, E.; Geilich, B.M.; Yazici, H.; Webster, T.J. pH-controlled cerium oxide nanoparticle inhibition of both gram-positive and gram-negative bacteria growth. Sci. Rep. 2017, 7, 1-12. [CrossRef]

109. Mahboub, H.H.; Shahin, K.; Zaglool, A.W.; Roushdy, E.M.; Ahmed, S.S.A. Efficacy of nano zinc oxide dietary supplements on growth performance, immunomodulation and disease resistance of African Catfish, Clarias gariepinus. Dis Aquat Org. 2020, 142, 147-160. [CrossRef] [PubMed]

110. Dakal, T.C.; Kumar, A.; Majumdar, R.S.; Yadav, V. Mechanistic basis of antimicrobial actions of silver nanoparticles. Front. Microbiol. 2016, 7, 1831. [CrossRef] [PubMed] 